\title{
Los Novecentistas en Londres y la aclimatación del scientific romance en España
}

\author{
Mariano MARTín RoDRÍGUEZ \\ martioa@yahoo.com
}

\section{RESUMEN}

En las primeras décadas del siglo XX, muchos de los jóvenes intelectuales españoles novecentistas sintieron la necesidad de vivir en el extranjero para mejorar su preparación desde una perspectiva cosmopolita. Varios marcharon a Londres, donde se familiarizaron con las instituciones y la cultura británicas, las cuales dieron luego a conocer mejor en España. Entre los productos culturales aclimatados por ellos, destaca el género del scientific romance, cuyo maestro reconocido era H. G. Wells. Varios escritores españoles, tales como Miguel de Unamuno o Vicente Blasco Ibáñez, también cultivaron por entonces esta modalidad literaria, pero serían tres miembros de los intelectuales del llamado "grupo de Londres" los que produjeron las primeras manifestaciones auténticas y bien acogidas del scientific romance español, a saber, Sentimental Club (1909) de Ramón Pérez de Ayala, El archipiélago maravilloso de Luis Araquistáin y La jirafa sagrada (1925) de Salvador de Madariaga. Estas obras manifiestan una tendencia especulativa y satírica que recurre a una ironía que podríamos calificar de británica, al efecto de transmitir un mensaje de libertad intelectual. Su fusión de pensamiento, humor e imaginación razonada en un marco ficcional renovador son típicas de la mejor literatura de este grupo, cuya expatriación fue beneficiosa no sólo para su formación intelectual, sino también para la modernización y universalización de la literatura española contemporánea.

Palabras clave: escritores novecentistas, scientific romance, Ramón Pérez de Ayala, Luis Araquistáin, Salvador de Madariaga.

The "Novecentistas" in London and the acclimatization of scientific romance in Spain

\begin{abstract}
In the first decades of the $20^{\text {th }}$ century, many Spanish young intellectuals felt the need to live abroad in order to improve their training with a cosmopolitan worldview. Several of them went to London, where they familiarised themselves with the British institutions and culture, eventually making them better known in Spain. Among the cultural products adapted by them, we must mention the scientific romance, whose most famous practitioner was H.G.
\end{abstract}


Wells. Some Spanish writers, such as Miguel de Unamuno or Vicente Blasco Ibáñez, also cultivated this literary genre. However, three members of the so-called "London group" of Spanish intellectuals were who succeeded in producing the first genuine, representative and well-received Spanish scientific romances: Ramón Pérez de Ayala's Sentimental Club (1909), Luis Araquistáin's El archipiélago maravilloso, and Salvador de Madariaga's La jirafa sagrada (1925). These works show a speculative and satirical tendency that uses a British kind of irony to convey a message of intellectual freedom. Their fusion of thought, humour and reasoned imagination in an innovative fictional framework is typical of the best literature written by this group. Thus, the expatriation of its members was beneficial not only for their intellectual background, but also for the modernisation and universality of the contemporary Spanish literature.

Key words: novecentistas, scientific romance, Ramón Pérez de Ayala, Luis Araquistáin, Salvador de Madariaga.

Aunque las relaciones culturales entre España y el resto de Europa habían ido adquiriendo una fluidez creciente a lo largo del siglo XIX, lo que resultaba favorecido por la difusión relativamente amplia del castellano gracias al prestigio de su literatura, las circunstancias de atraso socioeconómico de España contribuían a un ensimismamiento del que costaba salir ${ }^{1}$, y cuya manifestación geopolítica era la práctica retirada del concierto internacional que acabó traduciéndose en la trágica soledad del Desastre de 1898. Esta catástrofe para el orgullo patrio supuso un aldabonazo a la conciencia, al haber probado sin ningún género de dudas el carácter geopolíticamente marginal de España, que tanto contrastaba con su protagonismo histórico anterior. Ante esta realidad, y aunque hubo quienes prefirieron recrearse en glorias pretéritas como ilusoria panacea de los males del país, hubo también muchos que abogaron por la adopción decidida de los valores técnicos y científicos de las grandes potencias industriales europeas, cuya civilización había que conocer de primera mano para entender mejor todo aquello que parecía faltar y adoptarlo o, al menos, ser conscientes del grado de dependencia del extranjero y obrar en consecuencia en todos los órdenes de la vida, incluido el intelectual. Ya antes de 1898 se conocía esta necesidad, pero fue verdaderamente después de ese año fatídico cuan-

1 Tras el paréntesis de la llamada Edad de Plata, fuerza es reconocer que no se ha vuelto a hacer demasiada justicia a la inclusión de la literatura española en un panorama europeo ignorado con orgullo o incomprendido por una falta secular de preparación: "El esclarecimiento del carácter de la cultura española moderna sigue siendo motivo de estudio permanente, pues quedan muchas cuestiones sin resolver; entre las necesitadas de investigación, me parece urgente que precisemos el carácter de las relaciones entre nuestras literaturas nacionales y las europeas. Un lector de las historias literarias sacará la impresión de que somos diferentes, una enorme península, donde las influencias extranjeras llegan meramente a suplir el genio nacional, cuando en realidad durante la época moderna resultamos deudores del entorno europeo. Tampoco digo que la diferencia se debe a que existimos geográficamente aislados por un obstáculo natural, la barrera que suponen los Pirineos, sino que la divergencia viene por la frontera levantada por una cultura mal preparada para recibir las novedades llegadas de fuera. Ninguna de nuestras ciudades, digamos, tuvo el carácter intelectual de Weimar, la patria de Goethe, ni nuestras universidades decimonónicas se comparan con las alemanas de entonces. Nuestra diferencia tiene un origen social, porque éramos una sociedad con menor preparación intelectual, y este factor debe, en mi opinión, ser tenido en cuenta a la hora de explicar las letras españolas" (Gullón 2005: 170). 
do las iniciativas de expatriación constructiva se hicieron más frecuentes, como indica la creación de corresponsalías de prensa en grandes capitales como Londres o Berlín, que se sumaban así a la "ventana" exclusiva e insuficiente de París. Ramiro de Maeztu, que por edad y opciones intelectuales y estéticas, puede considerarse el escritor puente entre el Grupo del 98 y los novecentistas ${ }^{2}$, expresó con claridad ese convencimiento en un artículo programático publicado poco tiempo después de su llegada a Londres como corresponsal. En el mismo, tras señalar que Inglaterra era el país más importante para la economía española, Maeztu denunciaba la ignorancia en España de los mecanismos de funcionamiento del Imperio Británico, lo que la colocaba en mala situación para defender sus intereses. El tradicional tropismo francés ocultaba a los españoles ${ }^{3}$ qué lugar convenía conocer mejor:

Londres, la monstruosa, encierra actualmente el secreto de nuestro porvenir. ¿Por qué no tratar de descifrarlo? Allí va a decidirse el provenir de nuestro comercio, como allí se decidió acaso la pérdida de nuestras colonias [...]. ¿Qué poder es ese? ¿Cómo funciona? ¿En qué nos amenaza? ¿En qué nos sonríe? ¿Cuál es el secreto de su fuerza? Para formarse opinión en estas preguntas formidables hay que estudiarlas sobre el terreno mismo, siguiéndolas a medida que las oscilaciones de la oportunidad las ponen sobre el tapete. Y para realizar satisfactoriamente esta obra, sería necesaria la obra concertada de un centenar de espíritus. (Maeztu 1905)

A esta tarea dedicó innumerables artículos, que fueron surtiendo resultado. En 1911, otro artículo suyo se titula significativamente "Desafrancesados" (Maeztu

2 Siguiendo en parte a Guillermo Díaz-Plaja (1975), entendemos por Novecentismo el movimiento literario que puso en marcha en catalán (Noucentisme) Eugeni D’Ors como reacción superadora de las tendencias literarias finiseculares. La literatura novecentista española (y la de tendencias paralelas en otros países, sobre todo en la Europa latina), se oponía al irracionalismo finisecular, al carácter autodidacto y bohemio de sus escritores y pensadores, a su subjetivismo posromántico, a su estilo floral y decadente. En su lugar, los escritores novecentistas se presentan como intelectuales burgueses, casi siempre de formación universitaria sólida y actitud racionalista y serena ante el mundo, un mundo que veían preferentemente desde una perspectiva universal. Esta nueva actitud se traduce estéticamente en un ideal de claridad clásica, en busca siempre del equilibrio, con un estilo pulcro y cuidado, que huye por igual del decorativismo y del desmañamiento, aunque lejos asimismo del juego arbitrario y provocador de las Vanguardias. El intelectual novecentista no pretendía revolucionar las formas, sino modernizarlas mediante una estilización que ayudara a aumentar la eficacia de su mensaje, tendente a afirmar el papel de las minorías cultas. Con todo, no era un arte de capillas ni torres de marfil, y el ideario novecentista rehuía los tecnicismos para poder ejercer una influencia dignificadora en la sociedad. De ahí que el ensayo, como fusión de pensamiento y literatura, fuera el género preferido de este grupo histórico, hasta el punto de que muchas novelas tienen un aire ensayístico pronunciado, igual que la poesía e, incluso, el teatro. Así, las obras especulativas de Ramón Pérez de Ayala, Luis Araquistáin o Salvador de Madariaga son, de hecho, narraciones-ensayo, lo que contrasta con los distintos planteamientos literarios de escritores de generaciones anteriores, como el vehementemente individualista y liricizante del Miguel de Unamuno fictocientífico o el más netamente aventurero y sin pretensiones intelectuales confesas de Vicente Blasco Ibáñez, mientras que el apologetismo de un Carlos Mendizábal Brunet está muy lejos del equilibrio y el gusto por la ironía de la mayoría de los novecentistas.

3 “....] nos asomamos a una mala ventana para mirar el mundo. España se ha pasado un siglo encaramándose a los Pirineos para contemplar a Europa. Pero Francia no es un buen punto de vista. París es la ciudad de todo el que aspira a divertirse, y acaso también la capital del mundo artístico. Pero todo el hombre que trabaja en grande pasa por Londres, como todo el que se divierte con cierto fasto pasa por París. Londres es la metrópoli del trabajo y del tráfico mundial. París nos ofrece un universo pulido y pintoresco, pero artificial y engañoso. Las realidades hondas y bruscas han de buscarse en Londres; allí se deciden los verdaderos sentidos de los pueblos”. (Maeztu 1905). 
1911) y en él consignó el triunfo de sus ideas: Francia había "dejado de ser para la mentalidad española la ventana del mundo", "una mitad de nuestros escritores jóvenes lee inglés o alemán" y, en fin, "el siglo XX marca un período de germanización y anglosajonización" (ibídem). En efecto, el desarrollo económico y militar de Alemania, su enorme producción cultural o la calidad de sus universidades despertaron un interés especial en el mismo Maeztu y en los novecentistas (los "escritores jóvenes" a los que se refería), como sugieren la trayectoria de José Ortega y Gasset o la estancia en Alemania, tras Inglaterra, de Luis Araquistáin; pero este fenómeno fue posterior (y menos intenso) a la moda que llevó tras los pasos de Maeztu a bastantes intelectuales que escucharon su recomendación de estudiar "sobre el terreno mismo" el mundo británico de manera sistemática, "concertada". Esta concertación no llegó a producirse como tal, deliberadamente, pero es verdad que Maeztu quiso erigirse, consiguiéndolo a menudo, en guía de los que iban afincándose en Londres, a los que prestó su apoyo y consideró integrantes de un círculo informal que denominó alguna vez el "grupo de Londres"4. Indicaba así que se trataba para él de un colectivo realmente existente, al que unían, en mayor medida que unas afinidades ciertas, aunque limitadas por la fuerte personalidad de cada expatriado, la influencia que su ambiente ejerció en ellos, sea por el conocimiento directo de las prácticas de una democracia verdaderamente liberal como escuela de tolerancia y de apertura mental, sea por las amistades entabladas con destacados intelectuales británicos, cuya repercusión se puede distinguir en el primero de los "chicos de Londres", Ramón Pérez de Ayala. Este se presentó a Maeztu nada más llegar a la capital inglesa en 1907 (Coletes Blanco 1984: 48-50) y, si bien no tuvieron una relación tan estrecha como la del primero con otros novecentistas, Pérez de Ayala siguió una trayectoria similar a la de Luis Araquistáin o Salvador de Madariaga ${ }^{5}$. Poco después de su llegada, el diario El Imparcial lo nombró corresponsal y nuestro autor empezó a enviar crónicas sobre distintos aspectos de la vida inglesa, haciendo más hincapié en las costumbres y la vida cotidiana que en la política o la economía. También tuvo la oportunidad de tratar a varios intelectuales del círculo de los socialistas fabianos, como H. G. Wells y George Bernard Shaw, cuyas comedias, en que ventilaba irónicamente cuestiones ideológicas de forma que se prestaban a la lectura igual o más que a la puesta en escena, dada la amplitud novelesca de las acotaciones, pudieron servir de modelo formal a una obra dramática que Pérez de Ayala publicó en la colección El Cuento Semanal (Pérez de Ayala

\footnotetext{
4 Maeztu utilizó las expresiones de "grupo de Londres" y "chicos de Londres" en cartas de entre 1910 y 1912 (Santervás 1990: 142 y n. 45).

5 El testimonio de Madariaga puede ser significativo al respecto: "Ramiro de Maeztu [...] tuvo el mérito de convencer a la opinión pública de la importancia de la civilización anglosajona, siendo el primero de una serie de hombres de letras que consagraron su juventud a la interpretación de valores anglosajones en términos de civilización española. Pronto se hizo necesario a todo periódico serio el tener un corresponsal en Londres, no un mero agente telegráfico, sino un escritor de raza, pensador y artista, capaz de captar la luz del ambiente inglés, proyectándola en vívidos colores sobre la opinión pública española. Este período vio la revelación de escritores como Ramón Pérez de Ayala y Luis Araquistáin, ambos formados en Londres y en la escuela de la vida inglesa" (Madariaga apud Coletes Blanco 1984: 90-91).
} 
1909), meses después de su regreso de Londres en 1908, y que tituló entonces Sentimental Club.

Esta "patraña burlesca" en un acto ha suscitado bastante bibliografía. Se ha estudiado con bastante detalle su carácter antiutópico (Font 1970, Myers 1981 y 1983, Albiac 1988), al ambientarse la acción en un futuro lejano en que toda la humanidad estaría sometida a un régimen comunista y radicalmente igualitario, hasta el punto de haber eliminado cualquier distinción externa en indumentaria o aspecto, así como la propia reproducción sexuada y todo lo que lleva consigo desde el punto de vista emocional, al efecto de controlar unos instintos que se opondrían al totalitarismo del sistema. Frente a esta situación, un disidente reúne a unos cuantos hombres y mujeres a quienes hace descubrir la verdadera historia y, lo que es más importante, el placer de amar, lo que, en el concepto de la obra, equivale a una resurrección de las relaciones de pareja tradicionales, de forma análoga a como en otras distopías antitotalitarias posteriores, como Nineteen Eighty-Four (1949) $(1984,1952)$ de George Orwell, ese tipo de relaciones connotaba la libertad íntima de los personajes (Martín Rodríguez 2009a). Esta dimensión sentimental no suele estar presente como motivo fundamental de la fábula en las numerosas respuestas que había suscitado la floración de utopías socialistas de gran éxito como Looking Backward (1888) (En el año 2000, 1892; Cien años después, 1910), del estadounidense Edward Bellamy, o News from Nowhere (1890) (Noticias de ninguna parte, 1903), de William Morris, que había sido uno de los libros comentados en un importante artículo sobre la "novela sociológica" (Builla 1896). Estos libros, como muchos otros que suscitó en Europa, incluida España, la controversia entre los partidarios de la organización capitalista y liberal frente al socialismo colectivista, se situaban en el terreno de la política y, a diferencia de las utopías y antiutopías posteriores, no prestaban demasiada atención ni a los elementos tecnológicos del futuro ni a la repercusión en unos individuos concretos de la ideología llevada a la práctica en gran escala, excepto When the Sleeper Wakes (1899) (Cuando despierte el durmiente, 1904-1905 en el diario El Imparcial), de Wells, limitándonos a las obras de amplia resonancia en la época.

No obstante, el mismo Wells no siempre siguió esa vía, y su libro de 1905 A Modern Utopia (Una utopía moderna, 1921) representó un regreso al utopismo sociológico de aire más ensayístico que novelesco que caracteriza el discurso (anti)utópico anterior a la ficción científica moderna. Pese a todos los matices que se impondrían a la hora de abordar un libro que se presta a lecturas divergentes, en mayor medida quizá que la mayoría de las utopías anteriores, la de Wells pecaba también de cierto idealismo unidimensional propio de un género propenso a exagerar en la apología de un sistema determinado, aun si tan escasamente totalitario como el socialismo fabiano subyacente a Una utopía moderna y objeto de una defensa no ficcional, el libro titulado New Worlds for Old (1908), que leyó Pérez de Ayala meses antes de publicar Sentimental Club y le sirvió de "estímulo más inmediato" (Coletes Blanco 1996: 19). La ironía y el escepticismo liberales ayalinos se vieron espoleados por una doctrina que se presentaba como una panacea, pero que tenía el fallo fundamental de no considerar lo suficiente la índole variada y contradictoria de la humanidad: 
Sentimental Club es, ante todo, una sátira de las obras utópicas y optimistas de Wells, en concreto de New Worlds for Old, en que se canta un futuro feliz basado en el progreso humano y la buena voluntad. Para Ayala, esto es imposible: el progreso aliena, despersonaliza y la buena voluntad se convierte en una suma de infortunios cuando adquiere una estructuración política de cuño socialista. (Coletes Blanco 1996: 21)

De acuerdo con el clasicismo novecentista, Pérez de Ayala antepone en esta obra el desarrollo equilibrado de cada personalidad a un dudoso bien común social si este es capaz de "provocar un alejamiento de la norma, en cuanto a relación armónica del hombre con el mundo y consigo mismo" (Coletes Blanco 1996: 17), una relación entendida en términos individuales. Desde este punto de vista, la elección de la perspectiva sentimental como mejor reactivo para poner de relieve el carácter antihumano de una ingeniería social de obligado cumplimiento (en Sentimental Club, el Estado reparte generosamente las penas de muerte) era perfectamente coherente con el propósito del autor, el cual empezó a explotar así unas posibilidades connotativas que escritores posteriores desarrollarían de forma más amplia y profunda en sus distopías. Sin embargo, Pérez de Ayala no confiere trascendencia trágica a un conflicto que, en inglés, Aldous Huxley o George Orwell plantearán, de todos modos, en términos similares a nuestro autor. En sus Estados totalitarios ficticios, el sexo y el amor son válvulas de escape intolerables, porque "any form of sexual activity other than that sanctioned by authority is seen as inherently subversive. [...] It is the instinctual, spontaneous, uncontrollable quality of sexual desire that makes it a threat to officially imposed conformity" (Ferns 1999: 122), si bien hay que señalar que no era el sexo como manifestación fisiológica lo que se perseguía, sino más bien su combinación con un sentimiento individualista tradicional, pero personalmente liberador.

Aunque deba descartarse cualquier influencia directa de la "patraña burlesca" en la distopía internacional, salvo quizá en el caso de $\mathrm{Huxley}^{6}$, cabe reconocerle a Pérez de Ayala su originalidad de precursor, pese a tener su obrilla un final abierto, más optimista (se da a entender que los conspiradores podrían triunfar) que en sus sucesores, como corresponde a una época en que el totalitarismo todavía era tan sólo una amenaza y no una práctica política extendida, como lo fue tras la revolución bolchevique y las distintas reacciones fascistas. De hecho, el mismo Pérez de Ayala la consideró lo suficientemente oportuna y vigente como para reeditarla en 1929, con algunos cambios textuales en el sentido de una mayor estilización formal, en la colección La Novela de Hoy y con un nuevo título, La revolución sentimental (Pérez de Ayala 1929), el cual disimula algo la inspiración inglesa patente en el antiguo de Sentimental Club, lo que no nos debe inducir a creer que no sea

\footnotetext{
6 " [...] otra novela breve de Ayala, novela de ciencia-ficción, escrita en 1909 y publicada en El Cuento Semanal con el título de Sentimental Club, que luego cambió por el de Revolución sentimental, coadyuvó tácitamente a la concepción del famosísimo libro de Huxley Brave New World, o Mundo feliz, en la versión española. Huxley aprendió el idioma español mucho antes de retraerse en México, y su amistad con Pérez de Ayala fue, en los años mozos, asidua". (Calvo 1980: 41).
} 
un buen ejemplo de scientific romance ${ }^{7}$, para lo cual no es óbice su forma dramática $^{8}$.

Si el espíritu del scientific romance se caracteriza principalmente por la convivencia de seriedad y juego ${ }^{9}$ en un artefacto literario que explota imaginativamente la ciencia y la tecnología ${ }^{10}$, Sentimental Club pertenece sin duda a esta modalidad. En las primeras escenas se sugiere mediante alusiones el desarrollo material de ese futuro totalitario, especialmente en materia de transporte aéreo y de construcciones gigantescas, cosa que se puede apreciar aún mejor en las bellas ilustraciones de F. Montagut de la primera edición. Pérez de Ayala se preocupó asimismo de justificar por medios racionales y técnicos la posibilidad de la conspiración. El promotor de la misma, Parménides, hace instalar unos "aisladores", "porque el espionaje del comité, gracias a esas ondas extrañas de que se sirve, todo lo penetra, de todo se informa; nada hay que escape a su conocimiento" (Pérez de Ayala 1909: 5). Estas ondas, como la

7 Hemos preferido mantener la denominación inglesa en vez de traducirla como "novela científica", porque este término no se refiere exactamente esa modalidad literaria de origen británico, ya que servía sobre todo para designar las ficciones científicas positivistas de Jules Verne y sus imitadores. El texto siguiente puede dar una idea de que ambos tipos se contraponían en cierto modo en la época que nos ocupa, correspondiendo el de "novela científica" más bien al tipo verniano: "Respecto de la novela científica, hay que descartar la hipótesis de algunos impugnadores de Wells evocando el nombre de Julio Verne, cuyas obras, de rica imaginación y profundo conocimiento de las ciencias experimentales; de gracia fina, de invención algunas veces profética y de un dominio de investigación y emoción creatriz dignos de las mayores alabanzas, son absolutamente opuestas a las narraciones tétricas, frías y misteriosas de Wells" (Astrana Marín 1911: 1). No obstante, también se utilizó el término de "novela científica" para designar el scientific romance wellsiano, como puede verse en el siguiente comentario de Eduardo Gómez de Baquero al hilo de una novela regeneracionista y efectivamente científica de Julio Eguilaz: "Un nuevo novelista, de incógnito tras el seudónimo de Roque de Santillana, se presenta al público con la novela El último héroe, correspondiente a un género que tiene muchos lectores, pero escasísimos cultivadores originales en España: la novela científica a lo Wells, que conserva en la literatura moderna el elemento maravilloso de las epopeyas antiguas, que pasó luego a los libros de caballería y que ahora, para ponerse a tono con el ambiente contemporáneo, se trueca en maravilloso positivo, fundado sobre premisas más o menos exactas de las matemáticas y las ciencias naturales" (Gómez de Baquero 1910: 1).

8 Aparte de que se ha podido debatir su adscripción genérica al teatro o al cuento (Myers 1981; Soldevila Durante 1981) y de que se han señalado sus limitaciones como producto escénico por obedecer "a un concepto de teatro literario entonces de gran aceptación" (Canoa Galiana 1980: 188), el scientific romance no tenía por qué ser forzosamente narrativo: se trataba de una modalidad formalmente proteica, que podía abarcar tanto textos en forma de guión cinematográfico (por ejemplo, Ape and Essence de Aldous Huxley, 1948) como obras dramáticas, como la imponente Back to Methuselah (1922) (Volviendo a Matusalén, 1926), de George Bernard Shaw.

" "...] scientific romance is always inherently playful and is never without at least a hint of seriousness. Both these things are inherent in the nature of the exercice and we should not fall into the trap of considering playfulness and seriousness to be contradictory. [...] This combination of playfulness and seriousness makes scientific romance inherently iconoclastic". (Stableford 1985: 9).

10 El scientific romance puede considerarse una rama histórica de la ciencia ficción o ficción científica, si definimos esta en los términos siguientes: "Science fiction is that class of prose narrative treating of a situation that could not arise in the world we know, but which is hypothesised on the basis of some innovation in science or technology, or pseudo-science or pseudo-technology, wether human or extra-terrestrial in origin" (Kingsley Amis 1962: 18), con la salvedad de que narrative tendría que sustituirse por fiction. No obstante, hubo scientific romances, como La jirafa sagrada de Madariaga, o El archipiélago maravilloso (salvo en su primera parte, donde la inmortalidad y la eterna juventud se obtienen por un procedimiento artificial) de Araquistáin, en los que faltan prácticamente las innovaciones técnicas, por lo que se ajustarían mejor al concepto, más amplio, de literatura especulativa: “[...] we shall use the phrase 'especulative literature' [...] to denote any work of fiction, including drama and narrative poetry, that specializes in plausible speculation about life under changed but rationally conceivable circumstances, in an alternative past or present, or in the future. Nearly all 'science fiction' adheres to this definition” (Wagar 1982: 9). 
televisión-espía del Gran Hermano (Big Brother) en 1984, sugieren la pesadilla de una intimidad imposible debido al uso totalitario de la tecnología, pero este motivo no lo explota el autor, ya que su propósito no es enfrentar todavía a los personajes con el Estado planetario, sino crear un espacio seguro en que Ulises pueda realizar su adoctrinamiento sentimental, el cual opera una inversión irónica del discurso utópico. En utopías como las de Bellamy, Morris y, en menor medida, Wells, el personaje que va descubriendo, y describiendo, el futuro procede a menudo a una comparación con el mundo referencial del presente de la escritura para poner de relieve las disfunciones de la contemporaneidad, todas las cuales se resolverían en ese porvenir perfecto, mientras que Pérez de Ayala se burla de esas ensoñaciones al presentar no sólo un futuro humanamente horrible, sino sobre todo al confrontarlo con ese presente que no sería tan malo como lo pintarían sus detractores, pues aparece como un ideal deseable para los personajes de la sociedad comunista. No obstante, Ulises no oculta ni mucho menos sus aspectos más negativos, como la guerra -"Se peleaban, sirviéndose de instrumentos y aparatos mortíferos y se mataban a millares. Ello era siempre por futesas" (Pérez de Ayala 1909: 12)-, o simplemente ridículos, como la moda o la institución monárquica - a la pregunta de "qué méritos, qué origen y fuerza" tenía el rey, Ulises responde que no la ha podido descubrir, tan sólo que "el tal rey unas veces era mucho más gordo y otras mucho más flaco que sus súbditos" (ibídem: 11-12)-. De este modo, el autor no sólo se ríe de la utopía, sino también de la actualidad, que el lector percibe desde una perspectiva inédita y crítica, conforme a un viejo procedimiento satírico renovado gracias al recurso a un extrañamiento de carácter fictocientífico ${ }^{11}$, el cual se traduce en un efecto especulativo y humorístico a la vez. En efecto, "la observación del presente como si fuera un pasado remoto e inoperante debe necesariamente producir una inadecuación que, con un ligero adobo de ironía, provocará la hilaridad" (Soldevila Durante 1965: 10). Pérez de Ayala utiliza profusamente este recurso en Sentimental Club, confiriéndole así un tono ligero y desenfadado, que puede apreciarse asimismo en su lenguaje, un español lleno de galicismos sintácticos deliberados que contribuye a la impresión de juego de toda la obra, que se convierte así en una suerte de distopía cómica. Pérez de Ayala se convirtió de esta manera en un pionero de la recepción creativa del scientific romance, pero este hecho no tuvo apenas consecuencias en la institución literaria, debido al silencio que rodeó la "patraña burlesca", tal como era habitual tratándose de una publicación en una colección periódica de consumo, que rara vez suscitaba reacciones críticas.

En cambio, aparecieron varias reseñas, especialmente elogiosas en la prensa confesional, de la primera novela española en que es patente el influjo del scientific

11 Véase a este respecto una de las definiciones más influyentes de la ciencia ficción, entendida esta en sentido amplio: "a literary genere whose necessary and sufficient conditions are the presence and interaction of estrangement and congnition and whose formal device is an imaginative framework alternative to the author's empirical environment" (Suvin 1979: 7-8). Asimismo, desde un punto de vista pragmático, "la literatura de extrañamiento [...] crea un marco de referencia formal radical o significativamente distinto para mostrar las relaciones que establece la sociedad entre sí y con el medio que la circunda; es una literatura que no se verifica mediante el sentido común y que se dirige más al intelecto, al individuo como ser capaz de procesos racionales. Uno de los subgéneros de la literatura de extrañamiento es el utópico y dentro de él están la ciencia ficción y las utopías negativas o distopías" (Peña Frade 2002: 85). 
romance, en su suprema manifestación wellsiana, a saber, Elois y Morlocks, primera obra de ficción del ingeniero zaragozano Carlos Mendizábal Brunet (bajo el seudónimo de Dr. Lázaro Clendábims), que apareció el mismo año que Sentimental Club, aunque la había escrito al parecer "entre febrero y julio de 1908" (Uribe 2002: 37). Su trama sigue fielmente la de The Time Machine (1895) (La máquina exploradora del tiempo, 1926), a la que pretendía completar narrando el segundo viaje en el tiempo del protagonista, del que no había regresado en el romance de Wells. Según Mendizábal, en este segundo periplo, al inventor de la máquina le habría acompañado un hermano suyo misionero, que vio en el mundo descrito por el viajero temporal el resultado de unas tendencias aberrantes de su presente y, en primer lugar, una descristianización que pretende atajar en el futuro al que se dirigen.

La novela, que se divide en dos tomos, describe con todo lujo de detalles en su primera parte la bipartición radical de la sociedad entre "carentes" y "habentes" (Mendizábal Brunet 1909), fijándose sobre todo en las perversiones de estos últimos (promiscuidad sexual, eutanasia voluntaria mediante paroxismos de placer, culto a la belleza como religión, etc.), que los estaban degenerando mentalmente hasta convertirlos en los gráciles e idiotas elois. En la segunda parte, el misionero, tras la muerte de su hermano a manos de los morlocks, emprende una tarea de dignificación de elois y morlocks que desemboca en la reintegración de ambas razas en una única humanidad, que seguirá a rajatabla los preceptos cristianos que les ha imbuido con diversas artes y abundancia de sermones, todos puntualmente relatados y transcritos por el autor, que no deja pasar ocasión de insistir en la verdad del cristianismo, única solución a los problemas de la humanidad presente o futura. La ideología del libro, que no deja voluntariamente sitio alguno ni al humor ni a la ironía, está enfáticamente clara. "Si Wells superpone a la temática social perspectivas escatológicas propias de un filósofo de la Historia, Mendizábal la aplasta con ellas" (Uribe 2002: 39), hasta el punto de que cualquier consideración social o biológica, en el sentido evolucionista, se supedita al adoctrinamiento, con lo que no presenta un rasgo fundamental del scientific romance, tanto en su encarnación wellsiana como en la mayoría de las que le precedieron o sucedieron, a saber, su carácter reacio a cualquier explicación nítida de la realidad, una realidad ante la que el género adopta una posición distanciada, desencantada: "scientific romance is the romance of the disenchanted universe" (Stableford 1985: 9).

No obstante, la protesta de Mendizábal puede considerarse iconoclasta frente a la creciente secularización de su tiempo y no cabe duda de que comparte el intento de la mayoría de los cultivadores del scientific romance de pretender cambiar mentalidades y puntos de vista mediante un discurso que combine diversión y exigencia intelectual $^{12}$, pero la prédica es de lo más opuesto a un género que persigue más bien

12 "The lessons of scientific romance always had the power to change our minds by modifying our world-views, and they always have the intention, no matter how thickly coated they are with the sugar of mere amusement. [...] There is a crusading fervour about much scientific romance, because many writers consciously used it as a way of taking arms against the idols of the tribe and the idols of the theatre: false beliefs handed down by tradition and popular follies of the day. The weapons adopted to this purpose are varied, including melodrama and satire as well as reasoned argument, but in every scientific romance the noise of the battle can be heard". (Stableford 1985: 10). 
que ese cambio de perspectivas se produzca por medio de una confrontación de ideas o acciones ante las que el lector debe sacar sus propias conclusiones, sin que el autor pretenda imponer un mensaje unívoco. De hecho, la ironía es el recurso retórico preferido, como corresponde a una literatura moderna que confía gran parte de la interpretación al lector, de forma análoga a como, desde el punto de vista de la escritura, deja atrás la pretensión de la narrativa realista y naturalista de agotar el universo representado, mediante descripciones y explicaciones exhaustivas, en favor de una estilización que, aun dando impresión de realidad, confía su efecto a la capacidad de la imaginación del lector de construir entero el mundo ficcional a partir de los rasgos expresivos escogidos que se le ofrecen. Desde este punto de vista, Elois y Morlocks responde más bien a una estética decimonónica, en la tradición de la novela científica verniana, pues no deja cosa por describir con tal profusión de detalles que abundan los pasajes dignos de la novela científica más ingenieril, hasta el punto de que The Time Machine queda monstruosamente amplificada, aun descontando la reiteración sermoneadora. Esto no escapó a la atención de Ramiro de Maeztu, el cual le dedicó un artículo bastante negativo en el que declaraba que "sus dos volúmenes podrían compendiarse en uno solo, sin que se perdiese ni una sola idea ni matiz, y con enorme ventaja para el movimiento dinámico de la acción y consiguientemente del interior de la obra" (Maeztu 1909).

Hay que reconocer con todo que el disgusto de Maeztu no sólo se debió a la escasa pericia literaria de Mendizábal, sino a su desdén por el género: "cuando estos fantaseadores de la ciencia se meten a divagar acerca de la influencia de las futuras investigaciones sobre la naturaleza humana, entran en un terreno peligroso [...]. De ahí su candidez al ocuparse de las obras humanas", sin excluir a Wells, quien "si tuviera perspectiva histórica, no habría escrito ninguna de sus novelas sociológicas sobre lo porvenir" (ibídem). Aunque esto pueda explicar quizá que no cultivase nunca este tipo de literatura, esas palabras extrañan en el primer traductor de Wells. La publicación por entregas de su traducción de The War of the Worlds (1898), con el título de La guerra de los mundos, en la primera página del diario de amplia difusión El Imparcial, entre el 17 de marzo y el 21 de abril de 1902, fue el inicio de un amplio fenómeno de recepción de la obra wellsiana en España que llega hasta hoy (Mainer 1988 y Lázaro 2004, entre otros). La importancia del hecho no radica sólo en que fuera el primer contacto con los scientific romances, tal como Wells los denominó en una edición recopilatoria ${ }^{13}$, consagrando así un nombre que ya se utilizaba con frecuencia para designar esa especie literaria. Desde el punto de vista histórico, tal vez sea más significativo que a esa publicación acompañara un artículo del crítico, entonces muy prestigioso, Eduardo Gómez de Baquero, que suponía una toma de conciencia de la fantasía científica como "una nueva forma de lo maravilloso en literatura". Wells había procedido a "una restauración de lo maravilloso en literatu-

13 " $[\ldots]$ the term [scientific romance] was widely applied by reviewers and essayists to the early novels of H. G. Wells, which became the key exemplars of the genre. When listing his titles Wells usually lumped his sf and fantasy novels together as 'fantastic and imaginative romances', but he eventually chose to label the collection of his best-known sf novels The Scientific Romances of H. G. Wells (omni 1933), thus securing the term's definite status". (Stableford 1995). 
ra realizada con originalidad y aprovechando hábilmente los materiales de la actual cultura científica" (Gómez de Baquero 1902).

Frente a los libros de Jules Verne, entonces el autor más famoso entre los que habían usado la ciencia en la ficción y en cuyos libros, según este crítico, la literatura se supeditaba a la intención de divulgación científica, Wells primaba los criterios literarios. $\mathrm{Al}$ igual que otros escritores que estaban creando el nuevo género en Europa, como J.-H. Rosny Ainé, que también menciona, se trataba de "dar color de realidad histórica a lo fantástico" (ibídem), fundiendo en un nuevo tipo de ficción el aire verosímil del universo presentado (la "realidad histórica" y) lo "fantástico" de unas especulaciones que, tomando como base las sugestiones de la ciencia, abrían nuevas perspectivas a la imaginación y, de este modo, aportaban una nueva forma de ver el mundo. Tras esta lúcida apreciación de Gómez de Baquero de la novedad de otras obras de Wells, el ejemplo tardó un tiempo en fructificar en la literatura española. Si bien el editor de Barcelona Toribio Taberner había publicado traducciones castellanas de los principales scientific romances del maestro inglés (Lázaro 2004: 50), su ejemplo no fue seguido hasta Sentimental Club y Elois y Morlocks, pero estas dos obras no acertaron a imponer el scientific romance, sea por razones de sociología literaria, como en el primer caso, sea por no haberse entendido y aprovechado sus potencialidades en el segundo. De este modo, la segunda década del siglo XX fue prácticamente estéril para el género en España, si exceptuamos algunos relatos ${ }^{14}$, entre los que destaca el de Miguel de Unamuno publicado en El Imparcial (11 de agosto de 1913) titulado Mecanópolis, el cual sugiere, no obstante, la falta de sintonía real entre el escritor y el modelo inglés de ficción científica, que sólo conocería librescamente. Aunque Miguel de Unamuno había respondido a la crisis en torno a 1898 con un ansia de apertura que le había llevado a aprender idiomas y a empaparse de doctrinas y literaturas extranjeras, no había llegado a vivir en el extranjero durante su formación y tal vez por eso siempre le quedó un poso casticista que le llevaría en poco tiempo a evolucionar hacia un rechazo quijotesco del progreso técnico europeo en nombre de unos supuestos valores hispanos, de orden espiritual, presuntamente más acordes con las necesidades íntimas del individuo. La tecnología no podía saciar su anhelo de eternidad y de ahí su rechazo, que parece más subjetivo que político, tal como sugiere Mecanópolis, uno de los cuentos en que se manifiesta acaso con mayor claridad esta dicotomía unamuniana. En el mismo, "bajo la inspiración de Erewhon: or, Over the Range (1872) [Erewhon o Allende las montañas, 1926], novela precursora de S. Butler, se describe una ciudad deshabita-

14 Además de la novela corta La verdad en la ilusión (1912), de Luis Antón del Olmet, en la que se acumulan irónicamente los tópicos de las visiones futuristas de su época, y del cuento de asunto apocalíptico y antibelicista "El ocaso de la Humanidad" (1918), de Marcos Rafael Blanco Belmonte, destaca la narración cómica e iconoclasta "El Theological Palace", de Pompeyo Gener / Pompeu Gener, cuyo texto definitivo apareció en 1911 o 1912 en el volumen titulado Del presente, del pasado y del futuro como reelaboración de dos relatos anteriores, escritos en catalán y con mucha más sal gorda ("Un somni futurista espatarrant", publicado en Monòlegs extravagants en 1910, y "El telèfono ultra-mundial", 1911). En su primer párrafo, Gener alude a Wells como "humorista", lo que podría hacer pensar en un homenaje más bien burlesco: "Montados en la máquina de explorar el tiempo, del gran humorista Wells, habíamos graduado el resorte del empuje hacia adelante con tal fuerza y de tal manera, que en un momento nos hallamos en el siglo XXII" (Santiáñez-Tió 1995: 361). 
da y controlada por máquinas pensantes; la denuncia del mundo mecanizado, inhumano y fantasmagórico de Mecanópolis encaja perfectamente con las tendencias antiindustrialistas de su autor" (Santiáñez-Tió 1995: 24). De este modo, aunque la ciudad mecanizada ofrece al narrador protagonista todos los atractivos de la civilización y la cultura (higiene, toda clase de comodidades, información inagotable, arte, etc., gratis y a pedir de boca), el viajero en la ciudad acaba por volverse loco por la falta de calor humano y decide huir "donde no haya una sola máquina y fluyan los días con la dulce mansedumbre cristalina de un arroyo perdido en el bosque virgen" (Unamuno 1961: 128). Esta bella imagen final concluye con un toque lírico lo que Unamuno presenta siempre como una vivencia introspectiva (se trata de un sueño), de forma que esta vuelta a la naturaleza intocada ha de interpretarse como una opción personal del narrador. Sin embargo, no por ello deja de estar bastante clara la posición defendida en esta contraposición entre tecnología y vida, cuya nitidez excluye cualquier distanciamiento irónico, lo que contrasta poderosamente con la perspectiva irónica adoptada por el modelo reconocido de Unamuno, el citado Erewhon ${ }^{15}$, en el cual el verdadero objeto de la sátira no es tanto el maquinismo como la teoría de la evolución darwiniana, que Butler aplica satíricamente, como posibilidad, a las máquinas. Unamuno también alude a esa posibilidad ya que el protagonista se plantea si las máquinas podían tener un alma, aunque fuera mecánica, y que representaran así "la raza que ha de dominar la tierra deshumanizada" (Unamuno 1961: 127), dejando en suspenso si esto podía ser por eliminación de la humanidad o por una automatización psicológica del ser humano, sin aprovechar por tanto las grandes posibilidades narrativas del asunto. Pero Unamuno no pretendía seguramente escribir una ficción científica, sino más bien una parábola en la que su rechazo del desarrollo industrial moderno adquiriese fuerza de sugestión poética mediante el recurso a una serie de símbolos, entre los cuales el del abrazo del protagonista a un beduino, antes de quedarse a rezar bajo las estrellas, sin máquina alguna en las cercanías, puede ser también elocuente de sus preferencias. En cualquier caso, este breve relato, cuyo alto valor poético se combina con el interés histórico de representar la única incursión fictocientífica de su autor, puede servir de testimonio del atractivo creciente que ya ejercía por entonces entre los intelectuales españoles mejor enterados en materia de literatura internacional el llamado scientific romance inglés, del que Samuel Butler había sido precisamente uno de los primeros representantes, antes de la consagración definitiva de esta modalidad literaria gracias a Wells, cuya obra conocía Unamuno muy bien en cualquier caso (Chabrán 2007).

Tras esta incursión, problemática, de Unamuno en el scientific romance, hay que esperar hasta 1919 para que el género reaparezca con un mínimo de condiciones en la institución literaria española. Tras una larga sequía de traducciones de Wells, varios de sus relatos clasificables en el género aparecieron, en versión de un componente por edad del grupo novecentista o Generación de 1914, Alfonso Hernández

15 "Leyendo en Erewhon, de Samuel Butler, lo que nos dice de aquel erewhoniano que escribió el 'libro de las máquinas', consiguiendo con él que se desterrasen casi todas de su país, hame venido a la memoria el relato del viaje que hizo un amigo mío a Mecanópolis, la ciudad de las máquinas”. (Unamuno 1961: 124). 
Catá, en una antología titulada El país de los ciegos y otras narraciones, con un interesante prólogo de este escritor y diplomático hispano-cubano ${ }^{16}$. La iniciativa reviste cierta importancia histórica, pues inició una nueva oleada de versiones de Wells al castellano, con la publicación por el editor barcelonés Bauzá entre 1921 y 1926 de prácticamente todos sus scientific romances. Además, el mismo Hernández Catá sufrió "el influjo de las lecturas de Wells" (Alomar 1921: 8) en dos de las novelas cortas que publicó por entonces en su colección La voluntad de Dios (1921), especialmente en "El aborto", luego reeditada exenta en 1922 en La Novela Corta, lo que quizá pueda servir de indicio de su aprecio por un relato que nos parece, en efecto, de los mejores de la ficción científica española, dentro de un tipo antipastoral, bastante original, en el que se introduce el novum especulativo ${ }^{17}$ en un marco rural, descrito con técnicas del costumbrismo realista, de cuya pintura se desprende una visión no demasiado halagadora de la receptividad de la sociedad española frente al espíritu científico. No obstante, El aborto parece, en su tremendismo, una creación independiente del scientific romance, cuya verdadera aclimatación en España, tras el ejemplo aislado de Sentimental Club, está relacionado con la aparición de dos libros que obedecen al redescubrimiento de una añeja modalidad literaria con la que Gabriel Alomar, al reseñar El país de los ciegos y otras narraciones, ligó oportunamente a Wells, el cual no habría bebido sólo en las fuentes de la "fantasía científica de Verne" y del "psicologismo de lo anormal de Poe", sino también de "la tradición inglesa del proyectismo social de Tomás Moro y la del humorismo de Swift. Wells es, a la vez, un conciudadano de Utopia y de Liliput" (Alomar 1921: 8). El interés de este análisis radica en el adecuado reconocimiento del precedente swiftiano, del que procedería, pues, el "arte trascendental" de la estética de las narraciones de Wells, frente a la ficción científica aventurera o divulgativa:

[...] las narraciones de Swift no tienen, como ley estética, únicamente, un placer de fantasía, del arte por el arte; un interés de aventura, como para adormecer al

\footnotetext{
${ }^{16}$ El prologuista afirmó que "el nombre y gran parte de la obra de este ilustre escritor inglés son casi familiares a los lectores de lengua española; $y$, sin embargo, tememos que muy pocos tengan un concepto crítico de la significación de su esfuerzo" (Hernández Catá 1919: 9). A continuación, acometió la tarea de presentar el verdadero cariz de su literatura, partiendo de la ya clásica distinción con el modelo verniano: "El autor de Veinte mil leguas en viaje submarino se apoya en mecánicas posibilidades para forzar a seres desprovistos de toda levadura humana a perseguir absurdos caprichos; el autor de When the Sleeper Wakes toma pretexto en desenvolvimientos del progreso mecánico para proyectar modalidades del espíritu humano con un rigor y una acuidad de psicólogo no menos metódicamente inducidas que las líneas generales de sus hipótesis científicas" (ibídem: 10). Y más adelante: "Verne recrea, distrae; se siente al través de su páginas este propósito dominante; Wells es un preocupado que nos infunde sus preocupaciones ligándonos a ellas con la incónsutil cadena de una imaginación poderosa, removedora, de cuyas dos alas una está siempre rozando la realidad y la otra las altas quimeras posibles" (ibidem: 11). Era esta atención a la dimensión humana, patente asimismo en las narrraciones de tipo mimético o realista de Wells, de las que también habló Hernández Catá en su prólogo, la que garantizaría su pervivencia literaria: "Cuando pasen los años y muchas de sus anticipaciones científicas hayan sido sobrepasadas por las realidades, aún se hallará enseñanza y deleite en sus libros, porque en ellos podrá siempre identificarse mucho de cuanto tiene el hombre de eterno en sus anhelos y en sus incertidumbres" (ibidem: 19). La fortuna póstuma de Wells parece acreditar la agudeza del análisis de Hernández Catá, el cual significó en cualquier caso uno de los puntos más altos de la recepción wellsiana en España en ese momento.

17 "SF is distinguished by the narrative dominance or hegemony of a fictional 'novum' (novelty, innovation) validated by cognitive logic". (Suvin 1979: 63).
} 
eterno hombre-niño. Tampoco tienen, como las novelas de Verne, una intención docente; no son producto de una intrusión abusiva de la ciencia en la poesía. Pertenecen, propiamente, al arte trascendental. Esa palabra, trascendencia, indica lo que llamaríamos su poder de ulterioridad. Todo el amargor de la vida, en su concepción pesimista late bajo aquellas páginas inmortales. Y ese mismo trasunto filosófico es el elemento más intenso de su belleza; ya que son bellas, porque nos comunican el escalofrío de nuestra mísera relatividad. (Alomar 1921: 8)

Esta "relatividad" equivale al enfoque de la realidad desde una perspectiva distanciada, que desencadena la cognición y el cuestionamiento de lo que antes se tenía por sabido, lo cual se presta soberanamente a un enfoque satírico sobre la sociedad o la naturaleza humana, usualmente de un alcance general que rehúye las urgencias circunstanciales del día, porque su objeto es la naturaleza del ser humano y la sociedad. Estos elementos, muy presentes, en el scientific romance, los había heredado este del viaje imaginario ${ }^{18}$, tan cultivado en inglés, como prueban el mismo Gulliver de Jonathan Swift o el muy influyente Erewhon de Butler y, desde este punto de vista, el juicio de Alomar hacía hincapié oportunamente en unas potencialidades que debieron de llevar a Vicente Blasco Ibáñez y, luego, a Luis Araquistáin a sumarse al nuevo auge universal del género ${ }^{19}$, si bien con diferente fortuna.

El mayor éxito de público correspondió sin duda al primero. Tras la aceptación mundial de Los cuatro jinetes del apocalipsis y su triunfal gira americana, el novelista valenciano acentuó su interés por los nuevos medios de ficción, empezando por el cine, a raíz de las adaptaciones de sus novelas en Hollywood y, en especial, de las ofertas de colaboración que recibió. El fruto de una de ellas fue El paraíso de las mujeres (1922 en volumen, tras su publicación por entregas en Blanco y Negro, entre el 9 de octubre de 1921 y el 19 de febrero de 1922), cuyo origen está en un guión que se le pidió, pero que él no pudo reducir al esquematismo de los argumentos cinematográficos del cine mudo. En su lugar, escribió rápidamente esa novela, que en principio ni siquiera había pensado publicar ${ }^{20}$, y que se nos presenta, pues,

18 Hemos caracterizado en otra parte este tipo de literatura, distinguiéndolo del emparentado de la utopía: "El objeto de éste [el viaje imaginario] suele ser también un espacio alternativo acotado (isla, planeta, etc.), como en la utopía, pero en él es la narración, y no la descripción, la que estructura la obra, pues ya no se hace hincapié en el lugar mismo, sino en el proceso del viaje, ocasión para observar dinámicamente y en sucesión temporal opuesta al estatismo utópico una serie de cuadros cuya variedad da pie al comentario, a menudo satírico, mientras que el viajero, que es siempre contemporáneo del autor para que la sátira pueda ejercerse sobre su sociedad, se ve inmerso en aventuras ante las que no le cabe permanecer impasible, pues de su actuación depende la continuación del trayecto, cuando no su misma integridad física" (Martín Rodríguez 2009b: 57).

19 Tal vez no sea casual que el cuestionamiento radical, social y antropológico, de los Gulliver's Travels de Swift se viera prolongado en una boga de continuaciones a raíz de la crisis de la Primera Guerra Mundial (y luego de la Segunda), cuya violencia extrema había hecho dudar de los ideales y discursos antes hegemónicos. Entre ellas, destacan las dos del húngaro Frigyes Karinthy, Utazás Faremidóba (1916) (Viaje a Faremidó, 1945) y Capillaria (1921), además de la de Blasco Ibáñez, mientras que el viaje imaginario sin falsilla gulliveriana, pero igualmente iconoclasta, no fue cultivado precisamente hasta entonces por Wells con su novela Mr. Blettsworthy on Rampole Island (1928), cuya versión castellana (Mr. Blettsworthy en la isla de Rampole), realizada por Rafael Cansinos Asséns, apareció ese mismo año y fue muy bien recibida por la crítica madrileña.

20 "Repito que jamás pensé que mi novela cinematográfica pudiera convertirse en volumen impreso". (Blasco Ibáñez 1922: 15). 
como un capricho ajeno a su escritura habitual, una especie de regreso a la libertad imaginativa de su infancia, cuando leía los Viajes de Gulliver ${ }^{21}$, libro que, en España, se había recibido sobre todo como obra para niños, sin mayor trascendencia, fidelidad ni cuidado en su traducción (Chamosa González 2005). Sin embargo, el libro revela la impresión que le produjo la civilización de los Estados Unidos, que se manifestaba, entre otras cosas, en un feminismo en la vida cotidiana que contrastaba con la mayor conservación de los roles tradicionales de la mujer en España y en el resto de Europa. En El paraíso de las mujeres se aplica una "estrategia de denuncia tanto de la marginación social de la mujer como de otros defectos de la sociedad" (Castillo Martín 2000: 820), sobre todo del militarismo, identificado con la masculinidad. En su nuevo Liliput, tras la partida de Gulliver, las mujeres se han hecho con el poder, invirtiendo completamente la situación de los sexos, gracias a la invención de un rayo que anula la capacidad destructiva de cualquier arma, hasta que los varones descubren un modo de desactivar a su vez dicho rayo y estalla su revuelta, cuyo resultado no se conoce, pues el protagonista se despierta: toda la historia no había sido más que un sueño, lo que limita ciertamente su alcance, de acuerdo con la falta de trascendencia satírica o ideológica declarada por el autor mismo:

Mi sorpresa fue grande al ver que el escenario era un libro al que algunos pretendían encontrar cierta intención filosófica y política. Hasta en los Estados Unidos -país donde las mujeres ejercen una enorme y legítima influencia-creen algunos, equivocadamente, que mi novela es a modo de sátira del feminismo contemporáneo. (Blasco Ibáñez 1922: 15)

Por supuesto, una cosa son las intenciones del autor y otra el resultado. La descripción de la ginecocracia liliputiense, como sociedad invertida, impone un extrañamiento completamente especulativo, que Blasco Ibáñez explota con humor y una ironía no demasiado frecuentes en su obra en tal grado. Si consideramos asimismo su recurso a unas innovaciones de orden tecnológico como motor y condición de la trama, por lo demás muy movida y atrayente, bien puede considerarse que esta nueva gulliveriada constituye un interesante scientific romance en nuestra lengua, como si la adopción del modelo gulliveriano, que está en el origen del género, lo encauzase de forma natural hacia el mismo, aun de forma poco menos que inconsciente para el autor. Este había insistido más bien en el carácter formalmente renovador de este "relato ligero" (ibídem: 16), cuya originalidad veía sobre todo en su carácter de ejemplo de una posible novela cinematográfica. Así, en su prefacio al lector parecía querer orientar la recepción hacia el reconocimiento de una novedad estructural que, en rigor, no existía en una novela con mucho oficio, pero más bien tradicional, lo que puede explicar a su vez que las críticas fueran más bien negativas ${ }^{22}$. Blasco Ibáñez

\footnotetext{
21 "Esta historia fantástica, que se despega por completo de mis novelas anteriores, no ha nacido verdaderamente ahora, pues data de los tiempos de mi infancia”. (ibídem: 14)

22 Por ejemplo: "En la literatura como en la guerra alternan las derrotas con los triunfos, y aunque El paraíso de las mujeres no sea el Waterloo de este Napoleón de la novela colorista, llamado Blasco Ibáñez, preciso es considerarlo como una ofensiva infortunada con ribetes de desastre. El paraíso de las mujeres es una narración entre inocente y grotesca, mala como película y aún peor como novela" (Santacruz 1922: 98).
} 
no ofrecía lo prometido, sino más bien un traspaso a la novela de las exigencias comerciales del cine de masas ${ }^{23}$, mientras que su verdadera aportación, la actualización del viaje imaginario con los recursos de la ficción científica, pasó casi desapercibida para la crítica española ${ }^{24}$, cuando podía haber contribuido más que nadie a su adopción gracias a su prestigio y fama. Le faltó sin duda la conciencia del género, así como su falta de verdadera conexión con los intelectuales novecentistas de educación inglesa que, poco después, sí acertaron a hacer arraigar su importación en los circuitos intelectuales de Madrid, si juzgamos por la acogida crítica que suscitó, en primer lugar, el viaje imaginario por una serie de islas del Pacífico de uno de los "chicos de Londres", Luis Araquistáin.

La trayectoria intelectual de Araquistáin es paralela a la de muchos miembros de su grupo generacional. Desde muy joven quiso salir de su país y, tras un paso no muy feliz por Argentina, "comunica a Unamuno su intención de trasladarse a Inglaterra para aprender el idioma a finales de 1907" (Santervás 1990: 136), para lo cual tenía la intención de conseguir algún puesto de corresponsal de prensa, cosa que consiguió pronto, pues empezó el año siguiente a mandar crónicas de Londres a diarios madrileños. Allí entabló una estrecha amistad con Ramiro de Maeztu. Aunque no coincidían ideológicamente, "predominaban en Araquistáin, respecto a Maeztu, la admiración y el respeto rastreables en su relación hasta 1911" (ibídem: 140), año en que el primero se trasladó a Berlín, como corresponsal de El Liberal, sobre todo para ampliar horizontes en la otra capital europea que más atrajo, por su pujanza económica y política, a los novecentistas. Sin embargo, la vida en la capital del Imperio Alemán, donde permaneció dos años, no debió de ser muy de su agrado, puesto que regresó a Londres en 1913 y allí permaneció hasta 1916, cuando regresó al país de origen para dirigir la revista España, habiéndose embarcado tanto en Londres como en Madrid en una campaña aliadófila apasionada, que hay que atribuir seguramente a su compromiso en favor de una democracia social avanzada. No en vano Araquistáin fue uno de los primeros intelectuales en sumarse al Partido

\footnotetext{
Y las condenas se han prolongado hasta hace poco. No sólo es una de sus libros menos estudiados, sino que también se le despacha sin contemplaciones: "Lo que él llamaba novela cinematográfica no era ni novela ni servía para el cine, y buena prueba de ello es El paraíso de las mujeres, que escribió a petición de Randolph Hearts, insoportable e insostenible como obra literaria e infumable como guión" (Reig 2002: 196-197). No vamos a entrar en polémicas sobre el valor de la novela, que en nuestra opinión no debe de ser tan escaso si consideramos que el libro sigue siendo una de las obras de ficción especulativa española más traducidas: como mínimo, se ha vertido al italiano, portugués, ruso, rumano y polaco, y a estas dos últimas lenguas muchos años después de la muerte del autor (Espinós Quero 1998). En cualquier caso, está todavía pendiente un estudio desprejuiciado de la novela en sus propios términos, esto es, como un ejemplo de (proto)ficción científica de calidad.

23 "El autor tiene que pensar, ante todo, en lo plástico, en lo aparente. Su visión tienen que ser superficial, esclava o servidora de un interés externo y efectista". (Andrenio 1922)

${ }^{24}$ No obstante, Eduardo Gómez de Baquero se refirió en su estupenda recensión de El paraíso de las mujeres a su doble relación con Swift y Wells, aludiendo precisamente a lo "maravilloso científico" como modalidad literaria que él mismo había anunciado en 1902 con ocasión de la traducción de La guerra de los mundos, a saber: "No es difícil distinguir el origen de los varios elementos que han entrado en la composición de la fábula novelesca de Blasco Ibáñez. En las líneas generales de su invención sigue a Swift; el elemento fantástico, de maravilloso científico, los rayos negros, los cables de las máquinas voladoras y de los buques sumergibles que defienden el paraíso de las mujeres, proceden de Wells o tienen en las novelas del célebre autor inglés un antecedente inmediato" (Andrenio 1922).
} 
Socialista Obrero Español, en cuyas filas desempeñó una labor política muy influyente, por la que es recordado sobre todo hoy, mientras que su producción literaria, sea ensayística (formada sobre todo por artículos de prensa, parte de los cuales recopiló en volúmenes temáticos), sea dramática o narrativa, ha caído casi en el olvido, pese a la estupenda acogida que tuvo en su época. De hecho, fue uno de los periodistas más brillantes de su tiempo, quizá el que más de los que pasaron por la escuela de costumbres inglesa.

Como corresponsal en Londres, donde coincidió con Pérez de Ayala y con Ramiro de Maeztu, enviaba Araquistáin unas crónicas vibrantes, llenas de ingenio y de erudición, en las que dejaba ver su admiración por la democracia inglesa, su vocación europeísta, y su constante apelación a la educación como "pedagogía social" y solución al "problema de España". (Barrio Alonso 2008: XVIII)

Esta actividad, que se tradujo en centenares de crónicas, tuvo con todo un efecto negativo en su productividad como escritor creativo, y no sólo por las exigencias de tiempo que le supondrían, sino sobre todo por su especialización creciente en un periodismo político acorde con su militancia. De hecho, su producción ficcional se limita prácticamente a los dos períodos en que casi abandonó la política activa, primero en la década comprendida entre 1921, cuando abandonó la militancia activa en el Partido Socialista Obrero Español (PSOE) por discrepancias relativas a la línea del partido en relación con la Unión Soviética y las dos Internacionales obreras, y 1931, cuando la proclamación de la Segunda República le abrió un campo de actuación que aprovechó para convertirse en uno de los grandes ideólogos del socialismo español hasta que la derrota republicana en la Guerra Civil lo obligó a exiliarse, época en la que retomó la escritura de ficción en una serie de obras que han quedado inéditas.

De ambos períodos, el primero fue sin duda el más fecundo. Aparte de varias obras teatrales de escaso éxito, publicó en La Novela de Hoy varios relatos, más interesantes, de un costumbrismo satírico contra usos españoles arraigados, sobre todo en cuestiones eróticas y sentimentales, en lo que coinciden con las novelas contra el honor de Pérez de Ayala, a las que recuerda en un tono menor. A estas obras se suman sobre todo dos novelas sui generis, Las columnas de Hércules (1921), que pone en solfa la corrupción de los medios periodísticos con una escritura farsesca e iconoclasta, y, en especial, la narración de las "aventuras fantasmagóricas" (Araquistáin 1923) vividas por unos marineros españoles en El archipiélago maravilloso (1923), cuya trama resumió el autor mismo en la introducción a la continuación inacabada de ese libro, que escribió en el exilio, titulándola Ucronia. Tras el naufragio del buque bilbaíno Amboto:

En uno de los botes embarcan dos hombres: el agregado Antonio Ariel, que hace las prácticas del pilotaje, y el marinero Plácido Sánchez. Estos dos náufragos arriban a unas islas misteriosas [...]. Ariel y Plácido Sánchez recalan primero a la isla de los Inmortales, así llamada porque sus pobladores han descubierto un específico contra la muerte. De allí huyen a la isla de los Zahoríes, que recibe este nombre de un cristal prodigioso, abundante en aquel país, que permite leer el pensa- 
miento del prójimo. Luego dan en Nueva Armórica, terrible ginecocracia donde las mujeres practican el infanticidio de los varones recién nacidos y matan por extenuación amorosa a los hombres que tienen la dulce desgracia de caer en sus manos. Por último se fugan de este amable infierno en compañía de otros cautivos, y en un barco abandonado, cuya tripulación ha sido atraída a tierra por las sirenas neoarmoricanas, prosiguen el accidentado viaje hasta las Filipinas. (Araquistáin 2011: 190, 191-192)

Cada una de estas islas representa simbólicamente la realización de una doctrina en boga en la época, con cada una de las cuales polemiza Araquistáin con el procedimiento típico del viaje imaginario de construir ficcionalmente una sociedad en la que la aplicación de una ideología, utópica o de otra índole, conducía a una serie de fenómenos aberrantes o ridículos que ilustraban con humor e ironía radicales el carácter igual de ridículo o de humanamente perverso, en opinión del autor, de las ideas o usos satirizados ${ }^{25}$. Así habían obrado Swift en su Gulliver o Butler en Erewhon, además de algún precedente menos conocido de Araquistáin ${ }^{26}$, el cual explicó en Ucronia a quiénes se habían dirigido sus dardos:

El archipiélago maravilloso [...] no es, propiamente dicho, una utopia, sino más bien una visión humorística de la vida tal como la sueñan algunas gentes: los que desesperadamente no quieren morir, como Miguel de Unamuno, cuyo Sentimiento trágico de la vida inspiró en parte "La isla de los Inmortales", la primera de El archipiélago adonde arriban los náufragos; los que con la ayuda de la psicología y la psicopatología modernas quisieran leer en el alma humana como en un libro abierto, divulgando a los cuatro vientos el secreto de las pasiones y móviles, y los, o mejor dicho, las que quisieran despojar al hombre de sus poderes tradicionales, reduciéndole a la categoría de nuevo semental, aunque muchos hombres, hay que reconocerlo, tampoco son otra cosa. Es un libro caricaturesco y ligero, que no merece ser clasificado entre los utópicos. (Araquistáin 2011: 195)

25 "Las tres aventuras isleñas de El archipiélago maravilloso constituyen otras tantas réplicas pesimistas de las utopías sociales y políticas del hombre contemporáneo. Todas ellas son alegorías del estado presente de la civilización occidental y se remontan de modo invariable a las épocas más arcaicas de la Humanidad para explicar su evolución y su insatisfactorio punto de llegada. De esa reconstrucción -para la que Araquistáin no duda en fusionar libérrimamente los esquemáticos estadios de Comte con las diferentes etapas de la historia europea - no se deduce una idea de progreso sino de regresión, la cual, de modo paradójico, arranca de los hitos de los que debía esperarse que potenciaran la primera [...]. Por lo que, en última instancia, las tres utopías isleñas de El archipiélago maravilloso constituyen una visión paródica, mordaz y desencantada tanto de las ideologías redentoras emergentes como, en general, de las frustraciones de la Europa de entreguerras". (Calvo Carilla 2010: 273-274)

26 En concreto, existen indicios (como el que ambas obras se desarrollen en islas imaginarias situadas "en alguna parte de ese vasto trozo de mar que media entre las islas Sándwich o Hawai al Sur y las Aleutianas al Norte", como precisa Araquistáin en Ucronia, y especialmente la estructura de la fábula en torno a la navegación de una isla a otra, tras describir sus sociedades y sus cosmovisiones ideológicas respectivas) de que nuestro autor pudo inspirarse en Die Insel der Weisheit (Las islas de la sabiduría) (1922), de Alexandr Moszkowski, "a marvelous eclectic utopian satire that sets out to demonstrate that all political policies, if taken to extremes, have absurd consequences" (Stableford 1987: 77). La diferencia radical entre ellas es que, en Moszkowski, las disquisiciones ensayísticas casi ahogan la narración, mientras que Araquistáin explota el atractivo aventurero de una trama en que los dos protagonistas se ven en peligro de perder la vida en cada isla, aunque acaben escapando. 
Pese a la humildad del autor, que consideraba que la "ligereza" de la obra no la hacía merecedora de integrarse en el corpus clásico de la literatura utópica, aquel contradijo implícitamente esa afirmación al proceder en otro pasaje a una defensa de esta modalidad frente a la presión realista tan intensa tras la Guerra Civil, cuando redactó Ucronia:

[...] tampoco puedo estar de acuerdo con quienes menosprecian las utopias, como juegos infantiles propios de mentes perezosas o desprovistas de aquellos altos dones de observación que al parecer exigen las obras de arte cuando quieren ser reflejo de la realidad circundante. En toda utopia digna de este nombre hay un fondo de realismo, desde la República platónica, que es una copia idealizada del Estado comunista de los espartanos, hasta Los viajes de Gulliver, donde Swift satiriza jocosamente a la sociedad inglesa de su tiempo. Lejos de ser puro juego de la imaginación, una buena utopia vale como quintaesencia de la realidad. El utopista finge colocar fuera del tiempo y el espacio lo que tiene más cerca de la mano y de su época. Simula soñar precisamente lo que más le mantiene despierto. (Araquistáin 2011: 191)

No sabemos si el autor ya tenía estas ideas tan claras y favorables sobre esta rama de la ficción especulativa cuando publicó la novela, pero resulta curioso observar que fueron evocadas en varios de los comentarios que suscitó la obra entre los críticos madrileños, para uno de los cuales, Gómez de Baquero, era la mejor obra de ficción del autor hasta entonces, según afirmó en su reseña ${ }^{27}$. En la misma abordó El archipiélago maravilloso como una "novela de la utopía", que reflejaba "lo que no existe en el mapa de la realidad", pero "puede existir en el mapa más ancho de los posibles". Lejos de ser un capricho arbitrario y absurdo, el discurso utópico podía aspirar a dar "color de verosimilitud" a lo "maravilloso" de la ficción y ampliar el realismo para que cupieran en él "la actitud del moralista y el satírico" frente a la humanidad, así como una visión filosófica de la vida, frente a un costumbrismo reductor:

El libro de Araquistáin une al interés literario el filosófico. La misión de la novela no se reduce a levantar los tejados de las casas de vecindad [...]. Las utopías no le están vedadas, y estos viajes pueden ser tan atractivos como el paseo por las escenas corrientes de la comedia humana, siempre que el guía acierte a dar colorido y plasticidad a las imágenes, como lo ha conseguido el autor de El archipiélago maravilloso. (Andrenio 1923)

$\mathrm{Al}$ éxito narrativo que suponía haber acertado a conferir una impresión potente de cosa vivida, con plena ilusión de realidad, a un universo imaginario que quedaba por definición fuera de lo empírico, se sumaba otro no menos difícil, el estilístico:

Mucho contribuye al agrado y al interés del nuevo libro de Araquistáin [...] el estilo sano, robusto, clásico, de este excelente prosista. El afán de novedad y de colo-

${ }^{27}$ Según Andrenio, el libro era "más maduro y acabado, a mi parecer, que su anterior novela, Las columnas de Hércules" (Andrenio 1923). 
rido, y hasta el prurito del arabesco, conducen a olvidarse del dibujo en el estilo, es decir, de la expresión clara, precisa, coherente, conforme con la gramática y con la lógica. El estilo de Araquistáin tiene, además de colorido, dibujo. (Andrenio 1923)

Fue este aspecto de la escritura el que se ganó a otro crítico e intelectual novecentista reputado, Cipriano Rivas Cherif, al parecer más reacio a esta modalidad literaria que Gómez de Baquero, quien la había defendido en otras desde sus inicios wellsianos en España. Para aquel, El archipiélago maravilloso no era una verdadera novela, sino una sucesión de ensayos, "expuestos por reducción al absurdo", presentados según patrones ficcionales bien conocidos, que triunfaba literariamente por la vividez de sus figuras:

[...] no son las maravillas del archipiélago maravilloso descubierto por Araquistáin siguiendo las rutas conocidas en los mares de la ficción novelesca, ni las peripecias -soslayadas siempre por su autor voluntariamente- de la sencilla intriga, lo que nos gana en su lectura, página tras página, sino el discurso alerta, vivo, evidenciado por alegorías, cuya ejemplaridad se manifiesta por las figuras que la representan, tanto como por la leyenda que las explica y corrobora. (Rivas Cherif 1923)

Por unas razones o por otras, queda claro con todo que El archipiélago maravilloso tuvo una recepción crítica muy positiva, y a veces hasta entusiasta ${ }^{28}$. Otros indicios sugieren la impresión que produjo entre los intelectuales. Por ejemplo, Azorín publicó poco después, en el diario $A B C$, un homenaje al libro en forma de cuento-crítica (Martínez Cachero 1985) titulado "La isla de la Serenidad", en la que describe otra isla maravillosa felizmente libre de vida política (Azorín 1923). En 1928 apareció la versión italiana del libro, con un prefacio asimismo entusiasta del traductor ${ }^{29}$. Sin embargo, el libro no se ha reeditado hasta nuestra reciente edición (Araquistáin 2011), salvo una reimpresión en 1925 y la publicación exenta de la sección de la isla de las Zahoríes en La Novela de Hoy, cambiando sólo el título (El cristal de doble visión, 1932), si bien el autor abrigó el proyecto de volverla a publicar por la época en que se encontraba exiliado en Londres ${ }^{30}$, tras la

28 "Hace tiempo que en España no se ha producido una obra literaria con tantos valores intelectuales, sin perder por ello los puramente artísticos, que atesora esta novela de Araquistáin”. (Ballesteros de Martos 1923)

29 "Non rammento di aver letto altra narrazione fantastica di viaggi, fuor dei celeberrimi di Gulliver, che tanto mi sia piaciuta come quest'Arcipelago Meraviglioso del principe tra i pubblicisti spagnuoli. La stessa concezione sarcastica della vita, quanto all'intima significazione, la stessa diformazione rigorosamente logica della realtà, quanto al procedimento tecnico. Con in più un dato fondamentale per il nostro spirito moderno e che nello Swift manca affatto: il pathos, il sentimento: un sentimento che vi prende talvolta alla gola tanto è penetrante". (Pillerich 1928: 5).

30 "En enero de 1950 anda buscando ilustrador para una novela suya de los años 20, El archipiélago maravilloso, que pretende reeditar con ayuda de Andreu Abelló, y ha pensado para ello en el artista catalán Antoni Clavé. Negocia además la publicación de una traducción francesa de la misma obra" (Fuentes 2002: 131). En nuestra introducción a El archipiélago maravilloso seguido de Ucronia, reproducimos varios pasajes de cartas de Araquistáin que revelan sus varios intentos frustrados de sacar a la luz juntas ambas obras (en español, pero también en inglés y francés) durante su exilio (Martín Rodríguez 2011: 44-47). 
Guerra Civil, al tiempo que escribía la mencionada continuación Ucronia. El proyecto no llegó a buen puerto, pero puede ser significativo que fuese en Inglaterra donde Araquistáin volviera a interesarse por una obra que respondía a una literatura eminentemente británica, como él mismo reconoció, aunque subrayando su originalidad propia, en una entrevista concedida en 1926. A la pregunta de si había pensado en Samuel Butler, al escribir su viaje maravilloso y, tras elogiar el humanismo "tan inglés" que "sólo Inglaterra podía dar esos tipos" tan completos como el del autor de Erewhon, respondió que El archipiélago maravilloso "no tiene de inglés más que el género" (Giménez Caballero 1926), esto es, el scientific romance que Araquistáin había hecho triunfar así en los medios intelectuales españoles. A este respecto, y aun sin entrar en consideraciones sobre el valor literario de la obra, alto en nuestra opinión, su buena recepción sugiere que la institución literaria española estaba lista para acoger respetuosamente estas ficciones, al menos las escritas por los componentes del grupo cosmopolita de la capital británica, un grupo que ya se consideraba una especie de "categoría literaria", tal como afirmó Ernesto Giménez Caballero en la citada entrevista a Araquistáin, al decirle que era "uno más de los 'escritores españoles que vivieron en Londres'”, junto con Maeztu, Pérez de Ayala, Madariaga, Ricardo Baeza y otros, que habían prolongado el movimiento de "las emigraciones liberales y el ansia de ilustración" (Giménez Caballero 1926). Fuera esto así o no (Araquistáin se mostró más bien escéptico al respecto), estos autores habían dado muestras sobradas del cosmopolitismo del que se habían empapado en el medio inglés, centro de un imperio mundial, y $E l$ archipiélago maravilloso también recibió elogios por indicar un "afán de universalidad", al rebasar "los límites de la nacionalidad por su ideación, por sus dotes temperamentales y por su cultura", un afán que, según el mismo cronista, "se nota en la generación intelectual que ahora se está imponiendo en España" (Ballesteros de Martos 1923).

De este generación formaba parte asimismo su representante más cosmopolita a juzgar por su trayectoria vital, como diplomático en la Sociedad de Naciones y uno de los padres del europeísmo, además de escritor plurilingüe, Salvador de Madariaga, que también fue uno de los componentes del "grupo de Londres" mencionados por Giménez Caballero. Había llegado a la capital británica en 1916 para trabajar en el servicio de información sobre la Guerra Mundial para el mundo hispánico del diario The Times gracias a la recomendación de Araquistáin, a quien le unía una estrecha amistad y que publicó luego varios artículos de Madariaga en España (Victoria 1990a: 18-20). En Londres sufriría la influencia ideológica de Ramiro de Maeztu, cuyas ideas de esa época contribuyeron a conformar su particular liberalismo organicista y jerárquico (González Cuevas 1989: 82-83) y al que Madariaga admiraba en cualquier caso "como el escritor español que más había hecho por divulgar entre el público español las formas de vida inglesas, rompiendo, así, con la tradicional hegemonía francesa" (González Cuevas 1989: 173), esto es, en su calidad de mentor del grupo londinense al que Madariaga se había incorporado algo tardíamente, pero con intensidad tal que sus primeras obras pertenecen más a la literatura británica que a la española. Por ejemplo, la primera novela que publicó, en 1925, lo fue en doble versión, primero en español (La jirafa sagrada o 
El búho de plata) ${ }^{31}$ y en seguida en su original inglés (The Sacred Giraffe, Madariaga 1925b). Aunque la atribuyó a un heterónimo de nombre hispánico, Julio Arceval, el prólogo de la edición madrileña no deja dudas sobre la lengua en que Madariaga había escrito esta primera y única incursión suya en el género de la ficción especulativa:

Apenas precisa explicar a quien este libro leyere por qué lo escribió el autor en inglés. Bien se echa de ver desde su primer capítulo que la descripción de la utópica Ebania no es sino pretexto para satirizar la civilización actual vista a través de la vida inglesa. Julio Arceval utiliza con singular acierto en esta sátira ya el paralelo, ya el contraste, ya un método más sutil que podríamos llamar la reducción al absurdo por trasposición del punto de observación a un porvenir muy lejano. Sólo quien, como él, puso en juego para conocer a Inglaterra excepcionales condiciones naturales de penetración psicológica y excepcionales condiciones personales de intimidad con gentes del país podía manejar tal asunto con tal atinada ironía. [...] He de confesar igualmente que esta misma riqueza del ambiente inglés del original ha sido uno de los obstáculos mayores con que he tenido que luchar como traductor. (Madariaga 1925a: X-XI)

Así, el uso expresivo de proverbios ingleses, los frecuentes retruécanos y otros juegos de lenguaje con palabras o motivos ingleses planearon sumas dificultades al propio autor para su trasposición al castellano y, aunque aplicó su principio de "traducción como recreación" (Garea Oya 2001: 255), el cotejo de ambos textos revela la naturalidad del inglés, mientras que en el español, "para que nunca olvidemos que se trata de una traducción, se juega constantemente con palabras inglesas, se incluyen notas del traductor, etc." (Risco 1986: 86), lo que falta naturalmente en The Sacred Giraffe. De esta manera, un escritor español había adoptado el scientific romance hasta en su idioma.

La ubicación genérica de esta novela no ofrece, en efecto, ninguna duda. La combinación característica de seriedad y juego del scientific romance es clave en el efecto cómico perseguido conscientemente por el autor, que declaró no querer limitarse a satirizar la vida británica, sino contemplar "con serena pasión todo el paisaje de nuestras preocupaciones modernas, desde el problema de los sexos al de las razas, desde el de las naciones al de las lenguas" (Madariaga 1925a: XI), entre otros muchos temas a los que aplicó el procedimiento bien conocido en el género de observar la actualidad desde un extrañamiento determinado por la ambientación en un futuro lejano, del que se desprende el humor ${ }^{32}$. En este caso, nos encontramos ante un mundo del año 6922 en un país africano, Ebania, donde gobiernan las muje-

31 “La jirafa sagrada, de Arceval, se escribió en inglés, y es probable que su versión original aparezca pronto en librería" (Díez-Canedo 1925), como sucedió efectivamente. De hecho, las reseñas inglesas, más numerosas y atentas que las españolas, ya son de 1926 (Victoria 1990b: 504-507 y 865).

32 "El sistema [...] de redescubrir trabajosamente lo obvio o de reducir a su implacable descripción fenomenológica, acaba por ser un resorte fundamental del humor de La jirafa sagrada" (Mainer 1987: 295). Se trata de un procedimiento análogo al empleado por Pérez de Ayala en Sentimental Club, aunque con la diferencia fundamental de que el propósito en Madariaga es sobre todo satírico y carece de la dimensión admonitoria de la "patraña" ayalina. 
res, las cuales excluyen a los varones, pese a la existencia de un "hominismo" más bien frívolo, de todas las actividades serias, desde la política, que remite burlescamente al sistema bipartidista británico, hasta las empresas intelectuales, que en esta civilización sin apenas tecnología son sobre todo de índole histórico y giran en torno al enigma de si alguna vez existió la raza blanca, cuyos escasos vestigios documentales se interpretan con cómico desatino. Las prácticas del pasado así deducidas parecen aberrantes a la luz de los valores de aquella época y lugares tan alejados del presente, con lo que se denuncian, por contraste, las contradicciones y limitaciones de la sociedad de entreguerras y, en general, de cualquier sociedad, desde una perspectiva relativista muy acorde con la actitud liberal de Madariaga, cuya escritura explota aquí a fondo uno de los tropos más comunes del scientific romance, la ironía, hasta el punto de que la mayoría de los elementos narrativos se supeditan al juego de la sátira. A este respecto, se ha afirmado que La jirafa sagrada consiste en "una serie ininterrumpida de episodios humorísticos con referencia en usos y creencias de nuestra civilización" (Sanz Villanueva 1987: 298) y, efectivamente, la delgadez de la intriga sentimental que sirve de hilo conductor de la trama apenas consigue conferir consistencia novelesca al libro, cuya estructura narrativa ha podido parecer de "escasa habilidad" (Mainer 1987: 295), hasta llegar a calificarse la obra de "ingenua e indigesta hasta lo ilegible" (Pemartín 1953: 179). Este juicio tajante, publicado en una época no demasiado propicia a una narrativa que no se ajustara a patrones estrechamente miméticos y que, entre otros, fue rechazada de plano por el historiador de la novela española Eugenio de Nora ${ }^{33}$, contrasta poderosamente con la valoración de un intelectual coetáneo de prestigio reconocido, para quien la ligereza de La jirafa sagrada era lo que mejor servía a la finalidad satírica esencial de la obra, ya que "por todas [sus páginas] corre abundantemente la ironía, y aun los matices más serios, si se piensa en la realización novelesca, asumen aspecto más convincente rebajando la solemnidad del tono narrativo" (Díez-Canedo 1925). Pero este crítico tenía la ventaja sobre los posteriores de conocer en su contexto qué era y de dónde procedía el scientific romance, tal como sugieren estas líneas:

En todas las novelas utópicas -en los Viajes de Gulliver y en los libros de Samuel Butler, en La conquista del Reino de Maya ${ }^{34}$, de Ganivet, y en El archipiélago maravilloso, de Araquistáin-, cuando se habla de ayer o de mañana, y de otra parte, se entiende hoy y aquí. Las verdades salen envueltas en risas, bromas y disfraces, como en un Carnaval. Carnaval completo, bullicioso, picante, hasta clásico, si se quiere, el que se anima en las páginas de La jirafa sagrada. (Díez Canedo 1925)

\footnotetext{
33 "Puede comprenderse que dado tan vasto y heteróclito programa la obra haya llegado a calificarse de 'ingenua e indigesta hasta lo ilegible'; tal juicio peca, sin embargo, de incomprensivo y parcial, como dictado por una peculiar indisposición dogmática, de tradicionalista español, para compartir o aceptar el sentido de la crítica relativista y escéptica que contiene La jirafa sagrada. De hecho, novela, en el sentido estricto y exigente del término, no lo es, pero el libro brilla, alternativa o conjuntamente, por la gracia, malicia e intención de las observaciones, referencias y juicio implícitos de utopista fantaseador". (De Nora apud Victoria 1990b: 508).

34 Esta obra ganivetiana no es en puridad un scientific romance, pero su carácter especulativo e irónico lo acercaban a la modalidad para los críticos de entonces, a la búsqueda de precedentes españoles suficientemente conocidos y reputados.
} 
Así pues, la lectura de esas obras, así como las de Wells, orientó la recepción de Díez-Canedo, que no juzgó La jirafa sagrada de acuerdo con un modelo novelesco con el que no tenía que ver, sino más bien con una tradición distinta, ya cuajada, dentro de la cual no desmerecía el libro de Madariaga. Antes al contrario, este contribuía así a apuntalarla en España, tras la publicación poco antes del viaje imaginario de Araquistáin, el cual hacía ya las veces de ejemplo paradigmático, si consideramos la cita anterior. De ambas obras, se puede preferir quizá El archipiélago maravilloso, cuyo efecto satírico y distanciador no se ve perturbado por la leve fábula sentimental que, en La jirafa sagrada, rompe quizás la unidad de tono sin aportar en cambio grandes ventajas narrativas, pero las dos constituyen seguramente los frutos literarios más granados de la aventura londinense del Novecentismo español, al menos en su variante especulativa ${ }^{35}$. Tras ellos, y los demás precedentes que hemos evocado, se puede decir que el scientific romance ya formaba parte del panorama literario del país, tal como demuestra la sucesión de obras relacionadas con él, sea por revelar su influencia, sea por reunir la mayoría de sus características distintivas.

Estudiar este fenómeno requeriría aún mayor espacio, por lo que nos limitaremos a enumerar, a beneficio de inventario y como acicate para futuros trabajos, una serie de títulos cuyos autores pueden dar idea de hasta qué punto el género fue cultivado sin ambages por escritores e intelectuales de intereses muy variados, pero en cualquier caso miembros más o menos reconocidos de la institución literaria, y no sólo dentro del grupo novecentista. Si por su carácter eminentemente intelectual, atrajo a novelistas de la llamada Generación de 1914, que siguieron los pasos de Pérez de Ayala, Araquistáin o Madariaga, tales como Francisco Vera -con El hombre bicuadrado (1926), una recreación fantástica y frívolamente burlesca de The Invisible Man (1897) (El hombre invisible, 1905), de Wells--, Wenceslao Fernández López - con una divertida fantasía evolucionista, La fauna reciente $\left(1928^{36}\right)-$, José Lión Depetre -con su ágil novela sobre el fin del mundo Las confesiones de CayacHaтиаса (1931)-, David Arias - con su anticipación bélica y, a la vez, alegato pacifista Después del gas (1935)-, Joaquim Maria de Nadal -con el relato, también pacifista, "El llamp blau", incluido en Novel-la extravagant (1935)- o Josep Maria Francés -con Retorn al sol (1936) ${ }^{37}$, donde el humor soterrado del escritor templa feliz-

35 "Más cercano [que especulaciones sociopolíticas como La conquista del reino de Maya, de Ángel Ganivet, o Paradox rey, de Pío Baroja] al ideal de la de la anticipación pura, o -en término de Buylla- a la 'novela sociológica', estaría el relato breve de Ramón Pérez de Ayala Sentimental Club [...] que antecede a dos obras de más bulto e idénticas miras: El archipiélago maravilloso (1923) de Luis Araquistáin y La jirafa sagrada (1924) [sic] de Salvador de Madariaga, las dos utopías de mayor fuste de la literatura española del siglo XX" (Mainer 1988: 153-154). Estas dos obras no son, strictu sensu, utópicas, pero su calificación con ese nombre sugiere la pervivencia de su consideración como ejemplos de esta modalidad por sus mismos autores, a juzgar por la calificación de ambos libros de utópicos tanto por Araquistáin como por Madariaga, así como para los críticos. Por ejemplo, Gómez de Baquero había titulado su reseña de El Archipiélago maravilloso "La novela de la utopía", y Díez-Canedo había escrito en la de La jirafa sagrada que "es una novela utópica; llamándola así podríamos entendernos desde el principio" (Díez-Canedo 1925: 2), lo que sugiere una denominación de uso común para esta clase de libros.

36 Esta novela corta, publicada por primera vez en la colección La Novela de Hoy, la reeditó el autor, cambiando sólo el título, ahora "Colofón fantástico", como remate independiente de El hombre que compró un automóvil (1932).

37 El autor la consideraba, significativamente, "una novel·la d'anticipació tipus H. G. Wells" (Francés apud Solé i Camardons 1998: 33). 
mente su extremo nacionalismo etnicista catalán-, también se sumaron a la moda otros mayores o más jóvenes, como José María Salaverría -con El planeta prodigioso o Un mundo al descubierto (1929), una narración finamente irónica sobre la humanidad vista por los marcianos-, Felipe Ximénez de Sandoval -con Orestes I (1930), una mordaz "burla política" dramática escrita en colaboración con Pedro Sánchez de Neyra-, Alfonso Martínez Rizo -con El amor dentro de 200 años (1932), de tema erótico y libertario- o los médicos Manuel Torres Oliveros y Federico Oliver Cobeña -con su única obra en colaboración, La Tierra $n^{\circ} 2$ (1933), en que se describe un variopinto planeta paralelo entre utópico y distópico-. Tras la Guerra Civil, la ofensiva del neorrealismo y la llegada de la ciencia ficción paraliteraria, primero sin gran reputación intelectual y luego adoptada como tal por varios autores de cierto renombre (por ejemplo, Jorge Campos, Francisco García Pavón, Antonio Mingote, Tomás Salvador o Manuel García-Viñó), acabaron prácticamente con el scientific romance, igual que había ocurrido en su país de origen.

No obstante, el círculo se cerró como se había abierto: si la expatriación de Ramiro de Maeztu y de los novecentistas en Gran Bretaña puede considerarse el elemento de historia cultural decisivo para su importación, tal vez tampoco sea una casualidad que sus últimas manifestaciones españolas dignas de recuerdo fueran principalmente obra de escritores transterrados ${ }^{38}$, sea por razones de trabajo, como el diplomático Agustín de Foxá, autor de la magistral xenoficción "Hans y los insectos" (1953) y de la comedia Otoño del 3006 (1954), cuya idea parece proceder en parte de La revolución sentimental ayalina, así como del viaje imaginario a Efímera o país donde el tiempo transcurre aceleradamente ("Viaje a los efímeros", 1958); sea por haber tenido que exiliarse, como Pedro Salinas, cuya "fabulación" La bomba increíble (1950) es probablemente una de las cumbres del género y, por ende, de la ciencia ficción española, cosa que apenas se ha reconocido hasta ahora (Moreno Serrano 2004-2006); Álvaro Fernández Suárez, con su utopía ambigua "La misteriosa ciudad de Aurora" (recogida en Se abre una puerta..., 1953); Arturo Souto Alabarce, con el cuento sobre el simbólico avance de una grisura univer-

38 Sin embargo, pueden mencionarse varias obras escritas en la propia España después de la Guerra Civil que se relacionan más o menos estrechamente con el scientific romance, si bien la mayoría de ellas prescinde casi por completo del humor, típico de esta modalidad literaria (y que pervive en las de los escritores emigrados), en favor de un tono más trágico, como signo de la mutación de los tiempos. Destacan a este respecto varias ficciones (post)apocalípticas, a menudo teñidas de un humanismo cristiano aconfesional, tales como las dos novelas pacifistas tituladas, respectivamente, Los días están contados (1944), de Cecilio Benítez de Castro, y Después de la bomba de hidrógeno (1961), de José Canellas Casals; el cuento "Arca número dos" (1950), de José Luis Sampedro; la comedia (dramática) Como era en un principio (1951), de los hermanos Jorge y José de la Cueva, o la novela sobre una ciudad científica que sobrevive a la destrucción del mundo llamada Crisópolis (1956), de José Luis López Cid. A estas obras se pueden añadir Bajo las constelaciones (1943), de Carlos Buigas, una miscelánea ambiciosa y original de ensayos de divulgación científica, meditaciones utópicas y narraciones futuristas; la novela distópica, contra el populismo demagógico, Marea verde (1951), de Jaime de Foxá; el cuento, excepcionalmente humorístico, "Un mono llamado Adán" (recogido en Te quiero, bestia, 1960), de Álvaro de Laiglesia, o el relato de mundos perdidos o arqueoficción "Gzwrrawtzicxm" (publicado en la colección titulada Un crim abstracte o el jardiner assassinat,1965), del novecentista Nicolau Maria Rubió i Tudurí, que raya a la altura de su predecesor The Country of the Blind (1904) (El país de los ciegos, 1919), de Wells, con la diferencia de que en la narración catalana se trata de una sociedad de mudos en lugar de invidentes. 
sal "La plaga del crisantemo" (publicado en el volumen homónimo de 1960), y, por último ${ }^{39}$, Esteban Salazar Chapela, el cual escribió en Gran Bretaña la novela, publicada póstuma, Después de la bomba (1966), una amable ficción postapocalíptica que se desarrolla en un ambiente y con personajes y motivos típicamente (o tópicamente) ingleses, reflejados con la comprensión de alguien que había vivido entre ellos muchos años. Así se confirmó finalmente una de las enseñanzas que se puede desprender de esta historia, a saber, el carácter benéfico a la postre de la expatriación para una literatura, como la española, tradicionalmente ignorante o desdeñosa, salvo honrosas excepciones, tanto de los vuelos de la inteligencia especulativa como del reflejo fiel de un universo mental cosmopolita, sobre todo si juzgamos por las obras en que la crítica hispánica suele preferir centrar su atención, dejando en la sombra fenómenos tan interesantes, al menos desde el punto de vista de la literatura comparada, como el de la aclimatación del scientific romance en el panorama cultural español.

\section{BIBLIOGRAFÍA}

ALBIAC, María-Dolores (1988): "Sentimental Club: una revolución sentimental en un mundo feliz", en Las utopías en el mundo hispánico: Actas del coloquio celebrado en la Casa de Velázquez (24/26-XI-1988), pp. 241-270. Madrid: Casa de Velázquez / Universidad Complutense.

ALOMAR, Gabriel (1919): "La fantasía de Wells". El Imparcial, 22/XII/1919, p. 3.

- (1921): "Impresiones de un lector. Tres novelas de H. Catá". El Imparcial, 28/VIII/1921, p. 8 .

AMIS, Kingsley (1962): New Maps of Hell. A Survey of Science Fiction. London: The Science Fiction Book Club / Gollancz.

ANDRENIO (Eduardo Gómez de Baquero) (1922): "Un nuevo viaje de Gulliver. El paraíso de las mujeres, por Blasco Ibáñez”. La Época, 25/III/1922, p. 5.

- (1923): "La novela de la utopía". La Voz, 6/VI/1923, p. 1.

ARAQUISTÁIN, Luis (1923): El archipiélago maravilloso (aventuras fantasmagóricas). Madrid: Mundo Latino.

- (2011): El archipiélago maravilloso seguido de Ucronia. Colmenar Viejo: La biblioteca del laberinto.

ASTRANA MARÍN, Luis (1911): "Consideraciones sobre un libro de Wells". La Correspondencia de España, 29/VIII/1911, p. 1.

AZORÍN (José Martínez Ruiz) (1923): "La isla de la Serenidad". ABC, 4/VII/1923, pp. 3-4.

BALLESTEROS DE MARTOS (1923): "El archipiélago maravilloso, por Luis Araquistáin". El Sol, 2/VI/1923, p. 2.

BARRIO ALONSO, Ángeles (2008): "Luis Araquistáin publicista aliadófilo y socialista”, en Luis Araquistáin, Polémica de la guerra, pp. XIII-LXII. Madrid: Fundación Largo Caballero.

39 Al menos en castellano, pues en catalán hay que mencionar por lo menos un scientific romance algo posterior, Andrea Víctrix (1974), de Llorenç Villalonga, quien señaló que la obra "es decanta fonamentalment de Brave New World” (Villalonga 1974: 9). 
BUILLA Y ALEGRE, Adolfo A. (1896): "La novela sociológica”. La España Moderna, VIII, 90, pp. 5-26.

CALVO, Luis (1980): “Memento de Ramón Pérez de Ayala”. ABC, 22/XI/1980, pp. 41-42.

CALVO CARILLA, José Luis (2008): El sueño sostenible. Estudios sobre la utopía literaria en España. Madrid: Marcial Pons Historia.

CANOA GALIANA, Joaquina (1980): "Pérez de Ayala y el teatro", en Homenaje a Ramón Pérez de Ayala, pp. 161-188. Oviedo: Universidad de Oviedo / Publicaciones del Departamento de Crítica Literaria.

CASTILLO MARTÍN, Marcia (2000): “¿Blasco Ibáñez feminista? Una lectura de la novela El paraíso de las mujeres", en Joan Oleza y Javier Lluch (eds.), Vicente Blasco Ibáñez: 1898-1998. La vuelta al mundo de un novelista. Actas del Congreso Internacional celebrado en Valencia del 23 al 27 de noviembre de 1998, tomo II, pp. 816-829. Valencia: Generalitat Valenciana.

CHABRÁN, Rafael (2007): “Unamuno y H. G. Wells: pensamiento y literatura”. Cuadernos de la Cátedra Miguel de Unamuno, núm. 41, vol. 1, pp. 13-26.

CHAMOSA GONZÁLEZ, José Luis (2005): "Swift's Horses in the Land of the Caballeros", in Hermann J. Real (ed.), The Reception of Jonathan Swift in Europe, pp. 57-78. London $\&$ New York: Thoemmes Continuum.

COLETES BLANCO, Agustín (1984): Gran Bretaña y los Estados Unidos en la vida de Ramón Pérez de Ayala. Oviedo: I.D.E.A.

- (1996): "Entre Wells y Huxley: Pérez de Ayala y su Sentimental Club", en Pilar Abad, José M. Barrio y José M. Ruiz (eds.), Estudios de literatura en lengua inglesa del siglo $X X$, tomo 3, pp. 11-24. Valladolid: Servicio de Apoyo a la Enseñanza / Universidad de Valladolid.

DÍAZ-PLAJA, Guillermo (1975): Estructura y sentido del Novecentismo español. Madrid: Alianza Editorial.

DÍEZ-CANEDO, Enrique (1925): "Salvador de Madariaga: La jirafa sagrada, o el búho de plata (Editorial Mundo Latino)". El Sol, 27/I/1925, p. 2.

ESPINÓS QUERO, Antoni (1998): La obra literaria de Vicente Blasco Ibáñez: catálogo de las ediciones. Valencia: Diputación de Valencia.

FERNS, Chris (1999): Narrating Utopia: Ideology, Gender, Form in Utopian Literature. Liverpool: Liverpool University Press.

FONT, María Teresa (1970): "La sociedad del futuro en Pérez de Ayala, Huxley y Orwell". Revista de Estudios Hispánicos, núm. IV, vol. 1, pp. 67-83.

FUENTES, Francisco (2002): Luis Araquistáin y el socialismo español en el exilio (19391959). Madrid: Biblioteca Nueva.

GAROA OYA, Eva (2001): "La traducción como recreación en la figura de Salvador de Madariaga”, en Ann Barr, M. Rosario Martín Ruano y Jesús Torres del Rey (eds.), Últimas corrientes teóricas en los estudios de traducción y sus aplicaciones, pp. 255-262. Salamanca: Ediciones de la Universidad de Salamanca.

GIMÉNEZ CABALLERO, Ernesto (1926): "Visitas literarias. Fogonazo a Luis Araquistáin". El Sol, 5/XI/1926, p. 1.

GÓMEZ DE BAQUERO, Eduardo (1902): "Una nueva forma de lo maravilloso en literatura. Las novelas de H. G. Wells". El Imparcial, 17/III/1902, p. 4.

- (1910): "Revista literaria. La tierra de los Guanartemes, por Luis Morote. Pelayo González, por A. Hernández Catá. El último héroe, por Roque de Santillana”. El Imparcial, 2/IX/1910, p. 1.

GONZÁLEZ CUEVAS, Pedro Carlos (1989): "La crisis del liberalismo en Salvador de Madariaga". Cuadernos de Historia Contemporánea, 11, pp. 73-102. 
- (2003): Maeztu. Biografía de un nacionalista español. Madrid: Marcial Pons.

GULLÓN, Germán (2005): "La edad de la Literatura (1800-2000)". Anales de Literatura Española Contemporánea, núm. 30, vol. 1-2, pp. 170-204.

HERNÁNDEZ CATÁ, Alfonso (1919): “H. G. Wells”, en H. G. Wells, El país de los ciegos y otras narraciones, pp. 7-20. Madrid: Atenea.

LÁZARO, Luis Alberto (2004): H. G. Wells en España: estudio de los expedientes de censura (1939-1978). Madrid: Verbum.

MADARIAGA, Salvador de (1925): La jirafa sagrada o El búho de plata. Madrid: Mundo Latino.

- (1925): The Sacred Giraffe. New York and London: Harper \& Brothers Publishers.

MAEZTU, Ramiro de (1905): "Problema vital. España e Inglaterra". La Correspondencia de España, 5/I/1905, p. 1.

- (1909): "Elois y Morlocks". La Correspondencia de España, 5/VI/1909, p. 1.

- (1911): "Desafrancesados". Heraldo de Madrid, 28/VIII/1911, p. 1.

MAINER, José Carlos (1987): "Madariaga y su apócrifo: las novelas de Julio Arceval", en César Antonio Molina (ed.), Salvador de Madariaga 1886-1986, pp. 289-296. La Coruña: Ayuntamiento de La Coruña.

- (1988): "Una paráfrasis de H. G. Wells en 1909 y algunas notas sobre la fantasía científica en España", en Jean-Pierre Étienvre y Leonardo Romero (eds.), La recepción del texto literario (Coloquio Casa de Velázquez-Departamento de Filología Española de la Universidad de Zaragoza, Jaca, abril de 1986), pp. 145-176. Zaragoza: Servicio de Publicaciones de la Universidad de Zaragoza.

MARTIÍN RODRÍGUEZ, Mariano (2009): “Géneros futuros: visiones de la mujer y las relaciones amorosas en Sentimental Club (1909), de Ramón Pérez de Ayala”, en Pilar Nieva de la Paz (ed.), Roles de género y cambio social en la Literatura española del siglo XX, pp. 263-278. Amsterdam: Rodopi.

- (2009): "La literatura especulativa de Agustín de Foxá", en Agustín de Foxá, Historias de ciencia ficción, pp. 7-93. Colmenar Viejo: La biblioteca del laberinto.

- (2011): "Las islas extraordinarias de Luis Araquistáin", en Luis Araquistáin, El archipiélago maravilloso seguido de Ucronia. Colmenar Viejo: La biblioteca del laberinto.

MARTÍNEZ CACHERO, José María (2000): "Una especie literaria ambigua: los cuentoscrítica de Azorín”, en El canto de las sirenas (Páginas de investigación y crítica), pp. 177-186. Oviedo: Universidad de Oviedo.

MENDIZÁBAL BRUNET, Carlos (bajo el seudónimo anagramático de "Dr. Lázaro Clendábims") (1909): Elois y Morlocks. Barcelona: Herederos de Juan Gili.

MORENO SERRANO, Fernando Ángel (2004-2006): "Recursos genéricos de la novela de ciencia ficción de Pedro Salinas”. Tropelías: Revista de teoría de la literatura y literatura comparada, núm. 15-17, pp. 411-421.

MYERS, Eunice D. (1981): "Sentimental Club: un cuento filosófico de Ramón Pérez de Ayala”, en Pelayo H. Fernández (ed.), Simposio internacional Ramón Pérez de Ayala (1880-1980), University of New Mexico, pp. 128-135. Gijón: University of New Mexico / Flores.

- (1983): "Sentimental Club: A Dystopian Narrative by Ramón Pérez de Ayala", in Gilbert Paolini (ed.), La Chispa '83: Selected Proceedings, The 4th Louisiana Conference on Hispanic Languages and Literatures, pp. 195-202. New Orleans: Tulane University.

PEMARTÍN, José (1953): "La obra de Salvador de Madariaga". Arbor, XXVI, pp. 173-217. PEÑA FRADE, Nayibe (2002): "La ciudad en la ciencia ficción (La literatura como ilustración y contraste de la teoría)". Revista de Estudios Sociales, 11, pp. 85-91. 
PÉREZ DE AYALA, Ramón (1909): “Sentimental Club”. El Cuento Semanal, III, 147, $22 / 10$.

- (1929): “La revolución sentimental”. La Novela de Hoy, VIII, 373, 5/VII.

PILLERICH, Piero (1928): "Prefazione", in Luis Araquistaín, L'arcipelago meraviglioso. Avventure fantastiche, pp. 5-6. Roma: Anonima Romana Editoriale.

REIG, Ramiro (2002): Vicente Blasco Ibáñez. Madrid: Espasa-Calpe.

RISCO, Antonio (1986): "La anti-utopía en la novela de Salvador de Madariaga". Revista de la Universidad Complutense, 1-4, pp. 80-89.

RIVAS CHERIF, Cipriano (1923): “Tres novelas originales”. España, 375, p. 12.

SANTACRUZ, Pascual (1922): "El paraíso de las mujeres. Novela por V. Blasco Ibáñez. Editorial Prometeo". Nuestro Tiempo, núm. 280, pp. 98-100.

SANTERVÁS, Rafael (1990): "Maeztu y Araquistáin: dos periodistas acuciados por la transformación de España”. Cuadernos de Historia Contemporánea, 12, pp. 133-154.

SANTIÁÑEZ-TIÓ, Nil (1995): De la Luna a Mecanópolis. Antología de la ciencia ficción española (1832-1913). Barcelona: Sirmio-Quaderns Crema.

SANZ VILLANUEVA, Santos (1987): "Madariaga, novelista", en César Antonio Molina (ed.), Salvador de Madariaga 1886-1986, pp. 297-314. La Coruña: Ayuntamiento de La Coruña.

SOLDEVILA DURANTE, Ignacio (1965): “De Sentimental Club a La revolución sentimental". Cuadernos Hispanoamericanos, 181, pp. 5-19.

- (1981): "Una cuestión de poética y una pregunta retórica en torno a Sentimental Club", en Pelayo H. Fernández (ed.), Simposio internacional Ramón Pérez de Ayala (18801980), Univ. of New Mexico, pp. 136-147. Gijón: University of New Mexico / Flores.

SOLÉ I CAMARDONS, Jordi (1998): “Introducció”, en Josep Maria Francés, Retorn al sol, pp. 7-48. Lleida: Edicions de l'Universitat de Lleida.

STABLEFORD, Brian (1985): Scientific Romance in Britain 1890-1950. London: Fourth Estate.

- (19873): "Science Fiction between the Wars: 1918-1938", in Neil Barron (ed.), Anatomy of Wonder. A Critical Guide of Science Fiction, pp. 49-88. New York \& London: R. R. Bowler Company.

- (19952): "Scientific Romance", in John Clute y Peter Nicholls (eds.), The Encyclopedia of Science Fiction, p. 1076. New York: St. Martin's Griffin.

SUVIN, Darko (1979): Metamorphosis of Science Fiction. On the Poetics and History of a Literary Genre. New Haven \& London: Yale University Press.

UNAMUNO, Miguel de (1961): "Mecanópolis", en Cuentos, Eleanor Krane Paucker (ed.), tomo 2, pp. 124-128. Madrid: Minotauro.

URIBE, Augusto (2002): "De las protomáquinas del tiempo a las anticipaciones de lo por venir", en La ciencia ficción española, pp. 25-63. Madrid: Robel.

VICTORIA, Octavio (1990): Vida de Salvador de Madariaga. Madrid: Fundación Ramón Areces.

- (1990): Obra de Salvador de Madariaga. Madrid: Fundación Ramón Areces.

VILLALONGA, Llorenç (1974): Andrea Víctrix. Barcelona: Destino.

WAGAR, W. Warren (1982): Terminal Visions. The Literature of Last Things. Bloomington: Indiana University Press. 